\title{
La producción agrícola no capitalista y su relación con el capital
}

\author{
Aqulles Montoya
}

\section{Estudlos prevlos sobre el tema}

En una publicación anterior* nos ocupamos de mostrar cómo y por qué la producción de valores de uso y la producción mercantil se encuentran subsumidas indirectamente en el capital, pero tales formas son abastracciones de la realidad, la cual se mantiesta bajo formas particulares tales como la producción doméstica, la producción campesina, la producción artesanal, la producción domiciliaria, etc.

Oulzás bastarla con atimar que los procesos de trabajo presentes en tales formas de producción se encuentran indirectamente subsumidos en el capital en tanto productores de valores de uso $y / 0$ de simples mercanclas y tal es nuestra hipótesis. Sin embargo, a este nivel de abstracción nos encontramos con otras explicaciones de la realidad, objeto de nuestro estudio, que difieren de la nuestra, de alli que sea preciso dilucidar nuestras coincidencias, asi como fundamentar nuestros desacuerdos. Al hacerlo pensamos que no solo enriqueceriamos nuestro propio planteamiento, sino que evitaríamos posibles objeciones de quienes comparten tales interpretaciones de la realidad.

\section{a) Bruno Lautler}

Este autor en su trabajo: La subsunción formal del Trabajo al Capital, sostiene que "el concepto de subsunción formal al capital es un elemento

\footnotetext{
- Vease Montoya. A. "La necesided Térice de la categorla Subsunción Indirecta del Trabajo en el capilal. Rov. Pealidad. Enero-Febrero de 1988.
} 
esencial para el análisis de la pequef́a agricultura". 1

Su tesis de que el campesino se encuentra formalmente subsumido al capital también la encontramos en otros autores tales como: Roger Bartra y Gustavo Esteva, mientras que Ann Lucas la lleva al límite, al punto de sostener que se trata de una subsunción real. En contradicción con ellos se encuentra León Zamosc quién rechaza la pretendida subsunción formal.

Veamos el planteamiento de Lautier, quien tanto como Esteva ${ }^{2}$ enfoca su atención en la "agricultura por contrato", y al hacerlo sefiala un nuevo - tipo de relaciones que se establecen entre el "pequefio campesino" y el capital, ya sea en cuanto comprador de medios de producción, lo cual denomina "amont", como en cuanto vendedor de productos, a lo cual llama "aval". En la primera relación destaca la compulsión a que se ve sometido el pequeño campesino a comprar determinados medios de producción lo que ha tenido el doble resultado de ofrecer un mercado importante para el capital de "amont", que se valoriza al dictar sus leyes y al acrecentar la sumisión del pequeño campesino a las exigencias financieras. $^{3}$

Aunque tal relación no la considera suficiente como para atribuirle el carácter de formalmente subsumido, sino un mecanismo de reforzamiento de la subsunción que se generaria por el lado de la venta 0 del aval. En esta relación destaca los siguientes elementos: a) el pequeño campesino no vende en forma directa ni al mercado de bienes de consumo, ni lo hace a un comerciante, sino a una industria, b) la producción es efectuada por contrato y "el precio lo fija el comprador, sin referencia al valor real del producto", c) además de ello, el pequefio productor se ve compelido a especializarse en la producción de un determinado producto, cuya compra está monopolizada geográficamente.

Por todo ello, Lautier, sostiene que el trabajador rural por contrato es un asalariado a destajo. Asi dirá: "El trabajador rural está sometido, y por medio de los precios fijados por el "aval", está constrefido a aumentar su tiempo de trabajo para reproducir su fuerza de trabajo a la vez que sus medios de producción: es en verdad un asalariado por piezas a domicilio".4

Luisa Paré, quien observa un fenómeno semejante en México denomina "proletarios a domicilio" a aquellos "campesinos" que producen bajo contrato materias primas para el capital: cańa de azúcar, algodón henequen, tabaco, etc. ${ }^{5}$

Por otra parte, Lautier considera que, "...la posesión individual de la tierra (por parte del pequeńo agricultor) es una de las garantias de mantención de la situación de subsunción formal". 6 
En resumen, el productor campesino francés, del cual se ocupa Lautier, cuando se relaciona con el capital en la forma previamente sefialada es un asalariado por piezas, fuente de plusvalía absoluta para las industrias de aval y subsumido formalmente al capital.

Tal como hemos comprendido y expuesto el planteamiento de Bruno Lautier no vemos ningún problema en aceptar que nos encontramos ante un asalariado por piezas subsumido formalmente al capital, lo que si nos parece cuestionable es que siga considerándolo como un campesino. $Y$ resulta paradójico que lo haga cuando el mismo se plantea la pregunta clave: "El problema central es, pues, el de saber si realmente el pequeño campesino vende su fuerza de trabajo". 7 A lo cual responde: "Sin ninguna duda, no hay un asalariado especificamente capitalista: el proceso de trabajo no se halla afectado por la división del trabajo, la jerarquia, el salario por hora; por el contrario, permanece semejante a lo que era hace dos siglos". 8

Realmente desconcierta, si sostiene que se trata de un asalariado por piezas, que es tan típico del capitalismo como el asalariado por hora, ¿por qué no considerarlo como un asalariado específicamente capitalista? Por otra parte, si argumenta que está subsumido formalmente al capital, ¿qué de extraño tiene que permanezca semejante a lo que era hace dos siglos? Precisamente cuando la subsunción es formal es que el capital toma el proceso de trabajo tal cual lo encuentra, pero lo somete a la relación salarial. Relación salarial que tratándose del salario por piezas se nos presenta doblemente misticada en tanto no sólo encubre que el trabajador vende su fuerza de trabajo, (salario por hora) sino que parece además que vende el producto de su trabajo.

Y Lautier, no lo ignora, asi dice: "Su trabajo se objetiva en el producto, pero en la venta de su producto sólo se realiza el valor de su fuerza de trabajo".9 No obstante, a renglón seguido reafirma que se trata de un campesino: "El pequeño campesino conserva su proceso de trabajo, que aparentemente organiza como quiere". ${ }^{10}$

En nuestra opinión si la relación que se establece entre el pequeño productor y las industrias de aval reviste las caracteristicas sefialadas, nos encontramos ante una relación salarial a destajo novedosa en la agricultura y por tanto, tales productores directos se relacionan con el capital como proletarios agrícolas y su trabajo se encuentra subsumido formalmente en el capital.

Ahora bien, el aceptar lo anterior no implica aceptar que cualquier productor agricola se encuentra subsumido formalmente al capital, si no se dan los elementos que posibilitan afirmar la existencia de una relación salarial, pues tampoco sería posible afirmar la existencia de la subsunción formal del trabajo en el capital, aunque si podria hablarse de una 
subsunción indirecta del trabajo en el capital.

Así encontramos en el mismo trabajo de Bruno Lautier, antes de que proceda a considerar al pequeño campesino como subsumido formalmente al capital, elementos que abonan nuestra hipótesis de su carácter indirectamente subsumido al capital. Refutando a quienes sostienen la tésis de la coexistencia de modos de producción dira: "...así, la validez de las teorias esbozadas más arriba depende de la afirmación de que el pequeh́o campesino (generalmente propietario de los medios de producción) que no tiene patrón al cual venda explícitamente su fuerza de trabajo, está marginado de la relación 'capital'.

Ahora bien, decir que el pequeño agricultor se encuentra al margen del capital significa que es él (y no el capital) quien tiene el dominio del proceso de producción en su conjunto... por lo tanto, esto significa que el agricultor es libre de cultivar o no la tierra, que es duefio de la realización del valor de su producto, de vender, en fin mercancías, a su valor". 11

Compartimos su rechazo de la coexistencia de modos producción y aceptamos que el campesino no está al margen de la relación capital, ya Marx decia en la Introducción del "57: "El capital es la potencia económica, que lo domina todo, (en) la sociedad burguesa".12

Ahora bien, el dominio que efectúa el capital como un todo sobre la producción campesina, en tanto no es directa ni inmediata, en tanto no media una relación salarial de cualquier tipo, a nosotros se nos revela como una relación de subsunción indirecta del trabajo en el capital.

El pequeho productor que no se encuentra en la órbita de la agrilcultura por contrato que parte de su producción la destina al autoconsumo y parte la realiza en el mercado a fin de satisfacer sus necesidades materiales, tanto de medios de producción como de medios de vida, presenta en su dinámica dos procesos de producción, que como ya veiamos, dan lugar a la subsunción indirecta del trabajo en el capital.

Si la unidad campesina además de realizar sus productos en el mercado también provee al mercado laboral fuerza de trabajo autoreproducida, cual generalmente sucede, ella presenta en su concresión los dos casos generales de subsunción indirecta del trabajo en el capital, de los cuales nos hemos ocupado detalladamente en los apartados anteriores.

Por tanto, si bien el trabajo de Lautier constituye un avance en cuanto a la comprensión de esa nueva modalidad del agro, cual es la agricultura por contrato, deja sin explicar la existencia de la producción campesina, la cual ciertamente no nos parece que pueda estar subsumida formalmente al capital y en este sentido compartimos la refutación que 
efectúa León Zamosc13, quien plantea:

"Hasta qué punto el argumento de la subsunción formal del trabajo campesino en el capital se basa en una interpretación correcta de la distinción que Marx formulara entre subsunción formal y real?

El itinerario de la respuesta exige comenzar por el propio concepto de subsunción del trabajo en el capital. Al respeto, Marx escribe:

"...La génesis del capital mismo, así como del proceso capitalista de producción, se funda ante todo en dos elementos: primero, la compraventa de la capacldad laboral, un acto que corresponde a la esfera de la circulación... El segundo elemento es el proceso real de la producción, en que se consume la capacidad laboral adquirida... Si se consideran ambos elementos ...el proceso en su conjunto se presenta como un proceso en el que, 1) se intercambia menos trabajo objetivado por más trabajo vivo, por cuanto lo que el capitalista recibe realmente por el salario es trabajo vivo; y 2) las formas objetivas bajo las cuales el capital se representa directamente en el proceso laboral, los medios de producción son medios para la exacción y absorción de ese trabajo vivo... El proceso de trabajo se subsume en el capital (es su proplo proceso), y el capitalista se ubica en él como dirigente, conductor; para éste es al mismo tiempo, de manera directa un proceso de explotación del trabajo ajeno."

El texto de Maxx muestra, con claridad meridiana, que la noción de subsunción se refiere al proceso de valorización del capital, a través de la relación de producción específicamente capitalista, ya que el trabajo que es subsumido en el capital aparece antes que nada como una mercancía en la esfera de la circulación."14

Aunque compartimos en esencia la refutación de Zamosc es preciso reiterar algunos puntos que expuestos con bastante antelación pudieran haberse olvidado: 1) La subsunción de la que trata Marx es la subsunción directa del trabajo en el capital, la cual no excluye la posibilidad de una subsunción Indlrecta. 2) Ciertamente la subsunción a que hace referencia Marx, trata de relaciones tipicamente capitalistas mediadas por la categoria salarial, la cual puede ser por hora o a destajo.

Por otra parte Zamosc agrega "...el intento de conceptualizar la relación entre campesinado y capital en términos de un proceso de subsunción formal se basa en una interpretación equivocada de lo que Marx plantea en el capitulo inédito. Las dos formas históricas que asume la subsunción del trabajo en el capital representan un proceso que tiene lugar al interior de la producción capitalista, y de ninguna manera se refiere a una relación entre esta producción y otras producciones no capitalistas paralelas."15 
A pesar de ser bastante radical en su rechazo, Zamosc no plantea una solución a la problemática, aunque sugiere una posible "alternativa de aproximación analítica, (la cual) debe explorar las distintas formas por las cuales el trabajo campesino es reproducido y subordinado a partir de la dinámica impuesta por las condlclones de reproducclón de los sectores capltallstas dominantes."16 Tal planteamiento nos parece que es compatible con nuestra explicación de la producción campesina, cuya existencia encuentra su explicación a partir de su carácter indirectamente subsumido en el capital. Asl páginas atrás deciamos: Estas formas de producción no capitalistas, bajo distintas modalidades particulares, se encuentran incluidas dentro de la lógica del capital, esto es, determinadas en su existencia y funcionamiento por las necesidades de valorización del capital. El capital mismo las ha convertido indirectamente en instrumentos de su propia valorización, al mismo tiempo que las subordina en tanto que exige y posibilita su existencia, ya sea que lo haga directa o indirectamente.

\section{b) Ann Lucas}

Esta autora en su trabajo: "El debate sobre los Campesinos y el Capitalismo en México"17 aunque mantiene la posición más extrema en cuanto a la comprensión y explicación de la relación entre los campesinos y el capital, quizás sea la menos coherente dentro de un análisis manxista y antes de proceder a su estudio era conveniente hacer referecia a los planteamientos de Zamosc, quien se apega bastante al a teoria de Manx, particularmente en lo que al tema de la subsunción se refiere, desarrollado en el Capítulo Sexto Inédito.

Su posición teórica la hace explicita primeramente polemizando contra Roger Bartra. Su planteamiento es el siguiente: "Al afirmar que los campesinos sólo están formalmente subsumidos al capital, Bartra indica que lo están a través del mercado y del intercambio. No reconoce que las relaciones económicas y sociales que los campesinos mantienen con el capital (aunque no asalariados) involucra la producción misma. O sea: no admite lo que en realidad tenemos, la subsunción real de los campesinos al capital" 18

Al sostener que las relaciones entre el campesinado y el capital van más allá de la esfera de la circulación, ésto es hasta la órbita de la producción y por ello, se trata de una subsunción real, Ann Lucas desdefiosamente hace a un lado el presupuesto básico y fundamental del fenómeno de la subsunción formal y real, cual es la relación salarial.

Zamosc, le diría a Ann Lucas: "Sólo cuando el trabajo se enfrenta coIno mercancía a los medios de producción, sólo cuando su apropiación se efectúa a través de la relación de producción capitalista, sólo entonces ese trabajo es efectivamente subsumido en el capital"19 
Por otra parte cabría decirte a Ann Lucas que la diferencia entre subsunción formal o real, en el sentido marxista, nada tiene que ver con que la relación entre el capital y el trabajo, se den a nivel de la circulación o a nivel de la producción; y que si sólo se dan a nivel de la circulación es una subsunción formal y que si se involucra la producción además de la circulación estariamos ante una subsunción real, cual lo afirma la autora. Tanto on la subsunción formal como en la real, están involucradas la circulación y la producción, es en la circulación donde se compra la fuerza de trabajo para usarse dentro de la esfera de la producción. La subsunción formal del trabajo en el capital se diferencia de la real en que en la primera el capital toma el proceso de trabajo tal cual lo encuentra, en cambio en la segunda lo modifica, de alli que a la subsunción formal corresponde el mecanismo de la plusvalía absoluta, truto de la prolongación de la jornada de trabajo o de la intensificación del mismo, y a la subsunción real el mecanismo de la plusvalía relativa, resultado de incrementar la capacidad productiva del trabajo.

Establecidas estas aclaraciones previas procedamos a analizar la argumentación de Ann Lucas:

"Hay tres relaciones sociales tundamentales entre el campesino y el capital que entrañan una subsunción real de la mano de obra al capital: 1) los campesinos venden productos básicos; 2) reciben crédito y 3) participan en la agricultura por contrato.

Cuando los campesinos venden productos básicos en el mercado, sin duda están sujetos a explotación; dentro de la esfera de la circulación que involucra un intercambio desigual... El campesino no puede sobrevivir sin vender al capitalista. La autosuficiencia no es su opción. El campesino no acumula ni valoriza captial. Esta obligado a relacionarse con el capital para sobrevivir, en forma semejante a un trabajador asalariado... al terminar un ciclo agrícola el campesino, para sobrevivir, se ve obligado a cultivar y a vender al capital durante el ciclo siguiente. Ambos, el campesino y el trabajador, están sujetos a una relación con el capital que es perpétua. La diferencia principal es que uno es asalariado, mientras que el otro no lo es". 20

Aún sin cuestionar las afirmaciones de Ann Lucas, no encontramos un solo argumento que re-afirme su tésis de la subsunción real a partir de esa primera relación. Sin embargo, casi todos sus planteamientos pueden ser incluidos en el marco de la subsunción indirecta.

Ello, se hace mucho más evidente en el siguiente planteamiento:

"Desde el punto de vista del capital, lo anterior se logra mucho mejor (el avance capitalista y el control de los trabajadores) al mantener la relación fundamental de clase indirecta, mediada: que los campesinos sean obligados a vender sus productos al capital bajo los términos 
dictados por este último. El capital se beneficia a través de la acumulación sin asumir ningún riesgo asociado a la producción".21

En cuanto a la segunda relación que establece Ann Lucas, nos parece que es un mecanismo tlpico de subsunción indirecta del trabajo en el capital. Veamos el plantemaiento de la autora:

"Cuando un campesino o un grupo de campesinos reciben crédito de la banca oficial o del Banrural, no sólo se vincula a los campesinos por medio de la circulación... sino con la producción también. Se requiere que los campesinos a quienes Bannural otorga créditos, aseguren la cosecha con ANAGSA. Esta es responsable de la cosecha solamente cuando los campesinos siguen sus instrucciones, que especifican cómo preparar la tierra, cómo plantar la semilla, qué semillas, usar, cuánto plaguicida aplicar, cuándo plantar, cuánta semilla por hectárea, cuándo aplicar y reaplicar fertilizante, etc.

El campesino debe de someterse a inspecciones de campo realizadas por personal del Banco y de la ANAGSA. El crédito oficial se organiza de manera que las decisiones esenciales en cuanto a producción no quedan en manos de los campesinos y son asumidos por el capital a través del Banrural o de alguna otra organización de financiamiento estatal, como puede ser ANAGSA. El crédito no permite a los campesinos producir libremnte en la forma que ellos elegirian. Este es el mecanismo que usa el capital para insertarse directamente en el proceso de producción, controlando a éste último y al producto para su uso. Aqui tenemos una real subsunción del trabajo campesino al capital sin la presencia de un salario".22

Cuando los campesinos reciben crédito, que no siempre to reciben, puede ser oficial o privado. Cuando reciben crédito privado es preciso que lo aseguren a través de una institución oficial, la cual será responsable si el campesino atiende a sus instrucciones técnicas. A su vez el campesino es sometido a inspecciones tanto del Banco como de la Aseguradora. El crédito no permite a los campesinos producir libremente. Es claro que en el fenómeno planteado por Ann Lucas hay una subordinación del trabajo campesino, pero es una subordinación mediada por el Estado, que posibilita al capital bancario y al capital como un todo convertir al proceso de trabajo es un instrumento de su valorización, pero no lo hace de manera directa, sino aprovechándose de las instituciones oficiales. Puede incluso el capital bancario inspeccionar el proceso de trabajo, pero no lo dirige. Si a todo ello agregamos el otro elemento que destaca Ann Lucas que no se trata de un trabajo asalariado, obviamente, no nos encontramos ante un fenómeno de subsunción formal ni real pero si ante un mecanismo típico de subsunción indirecta del trabajo en el capital. 
Respecto a la tercera relación que sef̂ala Ann Lucas: la agricultura por contrato, no ańade nada nuevo al fenómeno y podrian reiterarse las consideraciones efectuadas al análisis de Bruno Lautier, de suyo más completo. O sea que cuando se trata de la agricultura por contrato más que insistir en la apariencia campesina de los productores es preciso percatarse que la realidad esencial, fruto de la relación que se establece con el capital, es la de obreros asalariados a destajo o proletarios a domicilio como les denomina Luisa Paré.

c) Una tercera perspectiva la encontramos en "Para Leer el Capitalismo" de Michel Beaud, Bertrand Bellon y Patrick Francois, quienes en forma muy precisa, exponen:

"En el momento actual, nos parece que puede ponerse de manifiesto en las sociedades capitalistas una tercera forma de sumisión del trabajo al capital: es la que caracteriza, por ejemplo, a los pequeños productores agricolas; éstos no están desposeídos de sus medios de producción; continúan apareciendo como pequefios productores independientes; pero, en realidad, dependen cada vez más del capital al cual están sometidos, indirectamente por la intermediación de los mercados:

- Ya sea para la realización (industrias agricolas y alimenticias);

- Ya sea por sus suministros (industrias de material agricola, de fertilizantes y de productos para el tratamiento de los cultivos, de alimentos para el ganado);

* Ya sea su financiación (crédito, banco)

También por intermedio del mercado, del juego relativo de los precios de los suministros y de los productores agricolas, el capital hace producir para él a los "productores independientes", frecuentemente persuadidos de que trabajan para nadie más.

Calificamos a esta situación de sumisión Indirecta del trabajo al capital; indirecta, es decir, no directa dentro del esquema del trabajo asalariado, sino por intermedio de los mercados.

Esta sumisión indirecta parece caracterizar la situación de la mayor parte de pequeños y medianos productores agricolas, y también de numerosos artesanos que trabajan como subcontratistas o en concesión, por ejemplo, para el servicio de reventa de aparatos electrónicos, electrodomésticos, etc."23

Observan además que a la plusvalia extraida a los obreros subsumidos directamente al capital, "se agrega el valor que el capital extrae a los pequehos productores independientes de la agricultura y del artesano, sometidos indirectamente por intermedio de los mercados. Al 
bajar los precios de sus productos en relación a los suminstros, equipos y materiales que les son necesarios, el capital obliga estos pequeños productores a producir cada vez más en su provecho.

Siendo productores de plusvalía para el capital y por lo tanto explotados, estos pequefios productores agrícolas y artesanales no pueden, sin embargo, ser asimilados a los proletarios de la clase obrera: continúan aunque sea de manera formal, jurídicamente, siendo propietarios de medios de producción y permanecen muy atados a la propiedad privada y a la explotación individual..."24

De lo expuesto por estos autores deseamos destacar los siguientes elementos:

- Hay una valorización indirecta del capital, los autores sefialan, incluso, los mecanismos de la misma.

- No media entre los productores directos y el capital: una relación salarial.

- Se caracterizan por creerse independientes, en tanto que conservan la propiedad jurídica de sus medios de producción.

d) Finalmente, deseamos exponer en forma resumida los planteamientos de Roberto Rubio, los cuales, además de ser los más completos que hemos encontrado, presentan las mismas inquietudes teóricas $y$ práctico-políticas que a nosotros nos animan.

En su concepción de la subsunción indirecta está presente el sentido de inclusión, asi plantea:

"La inclusión es indirecta cuando el trabajo-y el proceso de trabajo mismo- se encuentra "fuera" del ciclo de reproducción del capital pero contribuyen al proceso de acumulación del mismo". 25

Tal afirmación la efectúa por oposición al ciclo del capital productivo, como podría ser el ciclo del capital dinero, donde se observa que el proceso de trabajo, se ha convertido en el proceso mismo de producción del capital. Lo significativo seria que el proceso de trabajo contribuya al proceso de acumulación del capital, sin ser él mismo, un proceso de producción capitalista.

Además de lo anterior, él considera tres condiciones para que se de la subsunción indirecta, éstas son: primera, que exista una relación contradictoria entre el capital y el trabajo; segunda, que tal relación sea mediata; $y$ tercera, que sea una relación de hegemonia-subordinación. ${ }^{26}$

En cuanto a la primera, lo importante es que exista una oposicion entre el capital y el trabajo; en la segunda, destaca que, "El capital dinerario no encuentra inmediatamente al valor de la fuerza de trabajo, al trabajo vivo. Lo que encuentra es trabajo objetivado".27 
Tal sería el caso de un capitalista que ejerce funciones de comerciante o especulador. Cuando se trata del crédito, el capital dinero lo que encuentra es a un comprador de dinero. Respecto a la tercera condición, dira: "Es menester que la compra o el préstamo que efectua el capital dinerario signifique o lleve a colocar al proceso de trabajo bajo la racionalidad del capital, donde éste lo integrará como parte de su mismo proceso. ${ }^{28}$ Lo anterior a su vez implica un control por parte del capital, el cual puede efectuarse por intervención directa o indirecta en el proceso de producción.

A continuación procede a establecer que existen ciertos mecanismos particulares de subsunción indirecta, tales serian por ejemplo: los créditos o los contratos, en tanto trátese de capitales particulares. Pero realmente lo que le interesa es detenerse en los mecanismos generales de subsunción indirecta del trabajo al capital; los considera como generales en tanto trátase del capital como totalidad y en cuanto, abarcan todo tipo de trabajo no asalariado.

Entre estos mecanismos generales sefrala:

1) El mecanismo del mercado o sistema de precios $y$,

2) El Estado, particularmente, la Política Económica. ${ }^{29}$

Respecto al primero, senala "dos hechos que posibilitan la subsunción indirecta del trabajo al capital dentro del marco del intercambio general de mercancías:

a) Un sometimiento del proceso de circulación no capitalista al proceso de circulación capitalista.

b) Un control del proceso de producción de las unidades no capitalistas a través de ese 'proceso de circulación subordinado'"30

Posteriormente se preguntará:

"¿En qué forma -y por medio de qué mecanismos- el proceso de circulación subordinado de las explotaciones no capitalistas lleva a convertir al trabajo en instrumento indirecto del proceso de valorización del capital?"

A lo cual respoderá que es "a través del mercado de los productos, del sistema de precios, que el capital llega a establecer un dominio -indirecto-sobre el proceso de trabajo. $Y$ es debido a que éste se adecúa a un sistema de precios que expresa los intereses y las necesidades del capital que el trabajo se coloca como instrumento de su proceso de valorización". 31

En nota complementaria sefialará que, "La 'explotación' ya no se realiza por medio del salario sino de los precios de los productos que vende y/o compra la unidad campesina". 32 
En relación al segundo mecanismo general, expone:

"Es gracias a la Política Económica que el Estado mantiene, modifica e introduce la racionalidad capitalista dentro de los procesos de trabajo de determinada estructura económica nacional. Es gracias al crédito, a la regulación o fijación de precios y salarios, de la comercialización de los productos, de las inversiones estatales, de la asesoria técnica y de la investigación, del control sobre el comercio exterior, etc. que el proceso de trabajo llega a subordinarse a las necesidades del capital y se convierte en su instrumento".

Lo anterior es ilustrado a partir del movimiento del capital en la fase M'-D', la cual la interpreta como la necesidad de existencia de un mercado interno, de alli que el Estado mediante la Política Económica busqe "restablecer el poder de compra de la economia campesina" y en esa medida "colocar a los procesos de trabajo de la economia campesina en función de las necesidades del capital". 30

También to ilustra mediante otra fase del mismo ciclo, aquella que corresponde a la compra de fuerza de trabajo y medios de producción: D-M $M_{\mathrm{mp}}^{\mathrm{n}}$. El Estado a través de la Política Económica "no sólo pondrá en marcha algunas medidas que garanticen la existencia de cierta cantidad y calidad de mano de obra... y de medios de producción... sino también que los niveles de precios de esas 'mercancias productivas' no perjudiquen los intereses de la clase capitalista y la dinámica del capital en general. Aqui cabria ubicar a todas aquellas actividades... del Estado destinadas a abaratar o a regular los precios de los producos que conforman el valor de la fuerza de trabajo, así como de aquellos productos que constituyen materia prima o instrumentos de trabajo de los procesos de producción capitalista".34

Los últimos autores presentados on tanto que su perspectiva de análisis constituye nuestro punto de partida, nos parece que resultaria demasiado reiterativo el entrar a considerar en detalle sus planteamientos, de alli que sólo seńalaremos brevemente algunas diferencias:

- Tanto Michel Beaud y Compania, como Roberto Rubio parten en su análisis de las formas particulares: producción campesina $y / 0$ producción artesanal.

- No hay tampoco en ellos, resultado de lo anterior, un estudio de la subsunción indirecta del trabajo en el capital de carácter mucho más abstracto, que partiendo de la producción de valores de uso y/o producción mercantil, permita explicar cualquier forma particular de producción no capitalista.

- Igualmente se enfoca el fenómeno únicamente en lo que respecta a 
la producción mercantil simple y no en tanto que auto-reproducción de la fuerza de trabajo.

- Finalmente, en el trabajo de Roberto Rubio encontramos que una de las dos situaciones que presenta para ilustrar al fenómeno de la subsunción indirecta, se trata de la agricultura por contrato, de la cual ya hemos manifestado que no es válido seguir insistiendo en que se trata de una relación: capital-productor campesino, sino de capital-obrero agricola a destajo y, por tanto, no se trata de una subsunción indirecta del trabajo en el capital.

II. Los beneflclarios del decreto 207 una muestra tiplca de la Producción Agricola No Capltallsta (PANC) en El Salvador:

\section{a. Hlpotesls}

1a. La existencia de formas de producción no capitalista en una economia determinada encuentra su aplicación fundamental en el hecho de que sus procesos de trabajo se encuentran subsumidos indirectamente en el capital.

2a. La relación que se establece entre el capital y las formas de producción no capitalistas es una relación de expoliación, derivada del carácter indirectamente subsumido de sus procesos de trabajo en el capital.

3a. La subsunción indirecta del trabajo en el capital se revela en el hecho de que, sin mediar relaciones salariales, las diferentes formas de producción no capitalistas se encuentran incluidas en la lógica del capital y están subordinadas al mismo.

4a. Las distintas acciones del Estado relativas a la producción no capitalista tienen por resultado fomentar y/o asegurar la existencia de tales formas de producción, asi como posibilitar su expoliación por parte del capital.

5a. En tanto que la relación que se establece entre el capital y las formas de producción no capitalistas es una relación de expoliación, los intereses económicos de los productores no capitalistas tienen que ser opuestos a los intereses de la clase capitalista.

\section{b. Criterlos metodológlcos}

Mediante el decreto 207, o tase III de la relorma agraria, se buscaba transferir a los arrendatarios la propiedad de la tierra por ellos arrendada hasta un máximo de 7 has. son muchas las consideraciones que se pueden efectuar acerca de este decreto, sin embargo para nuestros propósitos baste con sefialar que el resultado fundamental obtenido, independientemente de las intenciones que se tuvieran ha sido la pro- 
moción de la PANC y siendo asi, nos interesa evidenciar cómo sus procesos de trabajo están subsumidos indirectamente en el capital.

Primariamente se impone la necesidad de demostrar que nos encontramos ante una PANC, los criterios que para ello utilizaremos son los siguientes:

1) Que la extensión de la explotación agrícola sea inferior a 10 has;

2) Que la produçción esté destinada al consumo interno y constituida, principalmente, por granos básicos;

3) Que la tierra sea de baja calidad y que se tenga poco o ningún uso de maquinaria y/o equipos agrícolas;

4) Que los ingresos provenientes de la producción no posibiliten al productor el liberarse de su participación directa en el proceso de trabajo, asi como tampoco constituir un fondo de acumulacion;

5) Que el productor conserve el control directo de su proceso de trabajo y pueda vender los productos del mismo; y

6) Que predomine el trabajo no asalariado.

En cuanto al primer criterio, los documentos oficiales reportan que el tamaño promedio de las explotaciones de los beneficiarios del 207 es de 1.5 has o de 2.4 has.35; según que se consideren las tierras obtenidas únicamente a través de FINATA, o bien que se incluyan tierras bajo otra forma de tenencia, como arrendamiento, compra, herencia, etc. Por otra parte, el decreto 207 sólo permitla reclamar la propiedad arrendada hasta un máximo de 7 has. Finalmente cabe sefialar que el $69.3 \%$ de las explotaciones tienen extensiones inferiores a las 2.1 has. ${ }^{36}$. Todo lo cual hace presumible que en su inmensa mayoria no excedan a las 10 has.

Respecto al segundo criterio, observamos que el $88.6 \%$ de la tierra cultivada se destina a la producción de maiz, maicillo, frijol y arroz. Siendo la mayor proporción la dedicada a maíz y la menor al arroz, $46.5 \%$ y $3.0 \%$, respectivamente. ${ }^{37}$ El destino de la producción es, obviamente, el mercado interno y su importancia dentro del mismo se revela al considerar que para la cosecha de $1983 / 84$, produjeron el $23.4 \%$ de la producción nacional de maiz, el $38.0 \%$ de la frijo, el $24.6 \%$ de la de maicillo y el $21.6 \%$ de la arroz. ${ }^{33}$ Por lo cual, parece claro que cumplen también el segundo criterio.

En lo que hace a la calidad del suelo de que disponen los beneficiarios del 207 , solamente el $11.4 \%$ se considera como bueno, incluyendo el bueno inclinado, medio inclinado y plano. A su vez, el $35.7 \%$ del total de la tierra es inclinada, ya sea buena, mala o regular, lo que estaria imponiendo una limitación física para el uso de maquinaria en más de un tercio de la tierra. ${ }^{39}$ También cabe agregar que únicamente el $16.4 \%$ 
posee los asi denominados "bienes de capial" por valor de $\$ 2.000$ y más ${ }^{40}$. Por tanto, resulta evidente que realizan su actividad productiva, mayoritariamente, en tierra de regular o mala calidad y a su vez, que es poco significativa la proporción de quienes poseen maquinaria y/o equipo agricola.

En lo que respecta al cuarto criterio seffalado baste con mencionar que en promedio las familias tuvieron anualmente un "ingreso neto total" de $\$ 3.659 .00$ en 1984 , del cual solamente el $34.1 \%$ es un "ingreso neto por producción" (SIC), el resto son ingresos provenientes de fuera de la parcela, ${ }^{41}$ en su gran mayoría generados por la venta de la fuerza de trabajo, ya sea en actividades agrícolas como no agrícolas. Los ingresos salariales constituyen el $62.5 \%$ de los ingresos de fuera de la parcela y son inclusive superiores a los considerados como "ingresos netos por producción".

Lo cual nos está claramente evidenciando que estos productos beneficiarios del 207, no sólo no pueden liberarse del trabajo en su propia parcela sino que la unidad familiar recurre a la venta de su fuerza de trabajo a fin de posibilitarse su reproducción, siendo esto así, parece innecesario insistir en las limitaciones que se les presentan a fin de lograr un fondo de acumulación con los ingresos provenientes de su propia producción.

En cuanto al penúltimo criterio, los estudios reportan que la venta de sus principales productos la hacen al Instituto Regulador de Abastecimientos (IRA), a los consumidores y a los intermediarios, siendo estos últimos quienes les compran en su mayor parte la producción. Para la cosecha de 1983/84, los intermediarios comercializaron el $87.1 \%$ del total42. Sin embargo, no se reporta una producción que haya sido efectuada por contrato y con una intervención del capital en el proceso de trabajo. Ciertamente el IRA exige el cumplimiento de ciertas normas de calidad, humedad, etc. pero ante ello el productor mejor opta por vender al intermediario que llega con su propio transporte hasta el mismo lugar de vivienda del productor. E importa destacar que tiene una libertad relativa de escoger a quien vender, libertad que ciertamente es formal, ya que la necesidad económica le obliga a aceptar, incluso, los menores precios del intermediario-transportista. Con todo, el productor controla su proceso de trabajo y vende los productos del mismo en el mercado.

Finalmente en lo que respecta al predominio del trabajo no asalariado, resulta obvio que teniendo las explotaciones de los beneficiarios del decreto 207, una extensión media tan reducida, como lo veíamos en el primer criterio, no necesitan de recurrir al trabajo asalariado en forma relevante. Aunque si lo hagan ocasionalmente.

Luego de haber contrastado los distintos criterios con la realidad de 
los beneficiarios del 207, nos parece que nos encontramos ante una producción agrícola no capitalista (PANC) típica, en la cual es común la producción para el mercado de la mercancia: granos básicos y a su vez, la producción de la mercancia: fuerza de trabajo, que se vende al capital.

El porqué de la presencia de esta realidad compleja es lo que explicaremos a partir de la subsunción indirecta del trabajo en el capital.

\section{c. La Producción Agricola no Capitallsta y el carácter Indirectamente subsumldo de sus procesos de trabajo en el capltal. Evidencla emplrica. Los productores agricolas no capltallstas de granos bá- sicos y los beneficlarios del decreto 207.}

El universo del cual nos ocuparemos en tanto está inmerso dentro del proceso de reforma agraria, deciamos que es la fase III, presenta muchas variaciones cuantitativas ya sea provenientes de la naturaleza procesual del mismo, de la realidad conflictiva que se vive en el pais, asi como también de aquellas procedentes de la naturaleza propia de la producción agrícola no capitalista.

Sin embargo, para fines operativos utilizaremos los datos reportados para el año de 1984, los cuales estiman el número de familias o el número de explotaciones agricolas no capitalistas en 63,648 con una superficie de 117,872 has. ${ }^{43}$ Comparados estos datos con los del Tercer Censo Agropecuario de 197.1 , representan el $25.4 \%$ de la PANC y el $30.0 \%$ de la tierra en que se efectuaba tal producción. ${ }^{49}$ ¿Qué relación guardan en la actualidad con el todo? No to sabemos porque no hay datos censales. Tampoco podemos estimarlos a partir de la tendencia observada de 1961 a 1971, porque inmersos durante esta década en una guerra civil cuyo principal escenario ha sido el agro, cualquier estimación sería carente de realidad. Lo que si podemos afirmar es que si a fines de la década pasada pudo haberse incrementado significativamente el número de PANC; para esta década debido a los efectos de la guerra con su secuela de desplazados y asesinados es probable que el número haya disminuido. Por tal razón nos parece que la población que estudiaremos es una muestra significativa del universo total de la producción agrícola no capitalista. Además de ello nos parece que se trata de la PANC típica en el país, con lo cual queremos decir que puede haber otras producciones agricolas no capitalistas que no se presenten bajo las formas de "explotaciones de subsistencia", "microfrincas y subfamiliares" o "minifundios". Pero que en tanto se trate de PANC estarán subsumidos indirectamente en el capital, aunque varien los mecanismos mediante los cuales se dé tal relación.

Una primera aproximación a nuestro objeto de estudio la podemos lograr a partir de dar respuesta a la interrogante siguiente: ¿por qué los 
PANC se dedican a la producción de alimentos agrícolas, principalmente, granos básicos? Se podría responder que es una práctica cultural secular; sin embargo nos parece que tal práctica pudo ser transformada con el surgimiento y desarrollo del capitalismo a partir de la generalización del cultivo del café, pero no lo fue; por el contrario, lo que se observa históricamente es un reforzamiento de tal práctica.

Desde nuestra perspectiva de análisis dos hechos parecen ser los fundamentales para comprender lo anterior. El primero es que al producir medios de vida se estaba posibilitando el auto-consumo, lo cual implica una auto-reproducción de la fuerza de trabajo aunque lo sea en forma parcial, pero con todo en su parte más importante. Por otro lado, siendo que el cultivo del café, como los otros cultivos de exportación introducidos ulteriormente, sólo demanda considerablemente fuerza de trabajo en forma estacional, para el capital agricola se presentaba como una exigencia que existiera una fuerza de trabajo que se auto-reprodujera, a fin de que los salarios de recolección de sus productos no se incrementaran.

Un segundo hecho es que al no efectuarse la producción agrícola de alimentos bajo la modadlidad capitalista es posible, y además beneficioso para el capital como un todo, mantener sus precios relativamente bajos, con lo cual se logra conservar los salarios de la clase trabajadora en general relativamęnte bajos.

Los mecanismosi de los cuales se vale el capital para ello son el acaparamiento de las tierras más fértiles, más planas y/o las más adecuadas para los cultivos de exportación, por una parte y por otra, el conceder al PANC una pequeña parcela: en un primer momento bajo la forma de colonato, luego como propietario minifundista y/o arrendatario. De tal modo que existiera fisicamente la fuerza de trabajo y a su vez que necesitara ser vendida durante una parte del aho, a fin de lograr su reproducción material, aunque fuese minimamente.

En lo dicho, está implícito el carácter indirectamente subsumido del trabajo delos PANC, en el capital. Trataremos de mostrarlo.

\section{c.1. La exIstencla de la PANC responde a la Ióglca del capltal.}

La existencia misma de la PANC está incluida en la lógica del capital. Se le permite su presencia en tanto es útil y necesaria para el capital agrícola y para el capital como un todo. De no responder a la lógica del capital o entrar en contradicción con su lógica, se le elimina. Históricamente algunas actividades particulares efectuadas bajo la forma de la PANC al entrar en contradicción con el capital han tendido a ser eliminadas, tales son por ejemplo: la producción de azúcar de pilón, de dulce de atado, de huevos, etc. Pero no sólo se le permite existir a la PANC, 
sino que a su vez se le fomenta, tal es lo ocurrido con el decreto 207, mediante el cual, el Estado busca asegurar la existencia de PANC garantizándoles tierra, asi como también crédito, asistencia técnica, etc.

El número de beneficiarios que obtienen crédito presenta un crecimiento constante. Para la cosecha $1981 / 82$ fueron 13,115 beneficiarios para 1982/83: 14,252; para 1983/84: 16,919 y para 1984/85: $18,915^{45}$.

Respecto a la asistencia técnica al comparar el número de beneficiarios que la recibieron en 1982: 3,956 con los de 1984: 14,445, ciertamente el incremento es considerable ${ }^{46}$. Tal asistencia para 1984 provino en un $44.6 \%$ del Banco de Fomento Agropecuario (BFA), el 27.4 del MAG, el $20.1 \%$ de FINATA y el resto de fuentes no estatales. EI Estado opera como un instrumento posibilitante de la subsunción indirecta del trabajo en el capital al promover y contribuir a la existencia de la PANC. Existencia que es tolerada por el capital en tanto le beneficie, de lo contrario el mismo se encarga de hacer que tienda a desaparecer, tal es lo que han hecho las granjas avicolas capitalistas o los ingenios azucareros capitalistas con los PANC de estas mercancias.

Por consiguiente, al estar la existencia de la PANC incluida dentro de la lógica del capital sus procesos de trabajo, que no guardan ninguna relación directa con el capital, se encuentran indirectamente subsumidos en el mismo.

\section{c.2. Los beneficlarios del decreto 207 y la auto-reproducción de su fuerza de trabajo}

La producción de valores de uso, estudiada como el primer caso general de subsunción indirecta del trabajo en el capital, ${ }^{*}$ está presente entre los beneficiarios del decreto 207. Estos, durante el año de 1982 destinaron el $59.2 \%$ de la producción bruta al auto-consumo y durante 1984, destinaron el $25.6 \%$ al mismo 47 . Parece ser que al incrementarse la producción disminuye la proporción que se destina al autoconsumo así en el primer año señalado la producción bruta promedio por familia fue inferior a la del segundo ańo. Lo cual tiene lógica en tanto los productores agrícolas no capitalistas, en general, venden su excedente.

Por otra parte, a nivel nacional las proporciones de la producción de granos básicos que se destinaron al auto-consumo en promedio durante el período 1980/81 a 1984/85, fueron las siguientes: maiz: $34,9 \%$, frijol: $39.4 \%$, maicillo: $22.3 \%$ y arroz: $5.1 \% 48$.

Ahora bien, estos PANC no sólo auto-reproducen su fuerza de trabajo mediante la producción de valores de uso, sino también mediante la realización de parte de la misma en el mercado, lo cual a su vez les

\footnotetext{
- Vease Revista Realidad. enero-Febrero de 1988
} 
permite adquirir otros medios de vida que no son producidos por ellos. Observados en tanto PANC, ciertamente existe una auto-reproducción de su fuerza de trabajo, aunque los frutos de su producción son insuficientes para lograr su auto-reproducción satisfactoriamente, de allí que se vean obligados a vender su fuerza de trabajo.

Si fijamos nuestra atención en la estructura del ingreso promedio familiar de los beneficiarios del 207, encontramos para 1984 un ingreso de 2,411 colones en promedio por familia, proveniente de actividades fuera de su producción, de los cuales el $62.5 \%$ tiene su origen en la ventas de fuerza de trabajo. 49 El resto corresponde a ventas de ganado, negocios propios, envios del exterior y otros ingresos, o sea que el $37.5 \%$ restante también puede considerarse como posibilitante de la auto-reproducción de la fuerza de trabajo en tanto que unidad familiar existente como PANC.

Ahora bien, lo interesante de esta dualidad: la auto-reproducción y la venta de fuerza de trabajo es que ello posibilita al capital: $1^{\text {2) }}$ la existencia de una fuerza de trabajo abundante en aquellas épocas del año en que la requiere, sin tener que cargar con sus costos de producción y reproducción, de alli que puede pagar salarios relativamente bajos, lo cual le genera una plusvalia extraordinaria. Consiguientemente los procesos de trabajo de los PANC se encuentran indirectamente subsumidos en el capital agricola. $2^{2}$ ) Pero a su vez del seno de la PANC también brota una fuerza de trabajo que emigra a la ciudad, ya sea en forma temporal o permanente, y va a buscar venderse al capital . Lo cual, por una parte al incrementar la oferta de trabajo en el área urbana contribuye a mantener comprimidos los salarios, favoreciendo de esta manera al capital; por otra parte, es una fuerza de trabajo producida totalmente fuera del circuito del "capital urbano" y parcialmente fuera del circuito del capital agrícola, por lo que el capital como un todo no ha tenido que cargar con sus costos de producción y reproducción. Ambos fenomenos se traducen en mayores posibilidades de valorización del capital, via compresión de los salarios y vía disminución de los costos reales de la fuerza de trabajo. Por tanto, también desde esta perspectiva es observable el carácter indirectamente subsumido de la PANC en el capital, o más precisamente, los procesos de trabajo de las PANC en el capital. $3^{\text {e) }}$ Pero hay más aún, la PANC no sólo cumple funciones de vivero, sino también de "refugio" y "asilo" de la fuerza de trabajo. En los períodos de crisis, cuando se incrementa el desempleo, el trabajador urbano puede acudir a su familia en el agro que se constituye en su seguro de desempleo y a su vez, cuando el capital industrial que gusta de la fueza de trabajo en su edad mas productiva le echa a la calle, puede retornar a su lugar de origen. De no desempenar tal papel la PANC, habrla una mayor urgencia de medidas de seguridad social, lo cual incre- 
mentaria los costos del capital. La no existencia de tales costos se convierte en otro instrumento de valorización extraordinaria del capital, lo cual viene a indicarnos una vez más el carácter indirectamente subsumido de la PANC en el capital así como el interés por parte del Estado en promover y asegurar su existencia, aunque a veces sólo se observe el aspecto político de sus acciones.

\section{c.3. Los beneflciarios del decreto 207 y la producción de alimentos "baratos". El fetlchlsmo del lngreso neto. La particlpaclón del Estado}

Tenemos ahora el elemento más relevante, cual es que los beneficiarios del 207 , suministran alimentos de origen agricola a precios que están por debajo de su costo de producción, con lo cual contribuyen a mantener bajo el costo de producción y reproducción de la clase trabajadora, posibilitando asi mantener bajos los salarios y consecuentemente disminuir los costos del capital, lo cual posibilita su valorización extraordinaria. Asi tenemos que para 1971, las PANC de granos básicos, clasificadas en los documentos oficiales como: "explotaciones de subsistencia" eran responsables por el $72 \%$ de la producción de granos básicos. ${ }^{50}$ En cuanto a los beneficiarios del decrelo 207, para 1984 generaban el $24.5 \%$ de la producción nacional de granos básicos. alcanzando en el caso del frijol el $38.0 \%{ }^{51}$.

Ahora bien, si los granos básicos fuesen producidos bajo formas capitalistas sus precios serian netamente superiores a los actuales, primero porque dentro de los costos de producción además de los insumos estarian incluidos los salarios de los trabajadores y segundo, por que comprenderían la parte correspondiente a la ganancia, a la renta absoluta y a la renta diferencial. Tales son los elementos constituitivos de los precios agricolas en la producción capitalista.

\section{c.3.1. ¿Preclos de garantla lguales a los costos de producclón?}

Pero, ¿qué sucede en la realidad, y particularmente con los beneficiarios del 207, en relación a la determinación del precio de los granos básicos? Por una parte existe lo que se denomina "precios de garantía", éstos son los precios a que ofrece comprar el Instituto Regulador de Abastecimientos (IRA). Por ahora supongamos que son establecidos en base al costo de producción. Sin embargo, a los PANC no les es posible vender toda su producción a través del IRA, primero porque no la compra; segundo, por que exige ciertas normas en cuanto a la calidad del producto y al grado de humedad que, de no ser cumplidos se traducen en descuentos en el monto a recibir; y tercero, por que el IRA no paga contra entrega, sino que el productor tiene que esperar varios meses para recibir el pago. Ante esta situación el PANC, vende a los intermedia- 
rios-transportistas o bien, directamente al consumidor, pero éstos le compran a precios inferiores que los establecidos por el IRA, con lo cual tendríamos una re-afimación de lo dicho previamente, esto es, que el PANC vende por debajo de su costo de producción. Veamos algunos datos demostrativos de lo anterior.

\section{Cuadro 1}

Volumenes comerclallzados de granos báslcos por los beneficlarlos del decreto 207. por agentes de comerclallzación, según productos. (En quintales). Cosecha 1983/84

Agentes

Productos

IRA Intermedlario Consumidor Total

\begin{tabular}{l|rrrr}
\hline Maiz & 93.153 & 1.142 .543 & 90.632 & 1.325 .328 \\
Frijol & 37.973 & 179.880 & 11.566 & 229.419 \\
Arroz & 11.469 & 170.638 & 4.028 & 186.135 \\
Maicillo & - & 382.963 & 29.596 & 412.559 \\
\hline & 142.595 & 1.876 .024 & 135.822 & 2.154 .441 \\
\hline
\end{tabular}

Fuente: Encuesta PERA. Citado en Segundo Perfil de Beneficiarios del Decreto 207. p. 54.

En el cuadro anterior se muestra que el IRA, sólo compra el $7.0 \%$ del maiz, el $16.6 \%$ del frijol y el $6.2 \%$ del arroz producido por los beneficiarios de 207, y si a los datos anteriores añadimos los precios a que compra cada uno de los agentes, asi como el precio medio ponderado (ver Cuadro No. 2), resulta evidente que los beneficiarios venden por debajo de su costo de producción, lo cual estaria implicando una transferencia de valor por parte del PANC, esto, es estaria siendo expoliado por el capital en tanto es éste quien resulla beneficiado en última instancia.

Además, es preciso aclarar que los precios presentados para el IRA, son los precios que en promedio compró el IRA a los beneficiarios del 207; sus "precios de garantia" para la cosecha de 1983/84 fueron de $\$ 30.000$ por quintal de maíz, $\$ 37.00$ por quintal de arroz en granza y de \$30.00 por quintal de frijol. La diferencia entre estos precios y los efectivamente pagados se explica por las deducciones que fectúa el IRA.

\section{c.3.2. Preclos al productor menores que sus costos reales de producclón.}

Ahora bien, si levantamos el supuesto de que los precios de sus- 


\section{Cuadro 2}

Preclos promedlos perclbldos por los beneflclarlos del decreto 207, por agente de comerciallzación, según producto. (En colones por quintal) Cosecha 1983/84

\begin{tabular}{lrccc}
\hline Productos & IRA & Intermediario & Consumidor & Total \\
Maíz & 28.14 & 25.32 & 23.64 & 25.40 \\
Frijol & 76.54 & 56.92 & 56.13 & 60.12 \\
Arroz granza & 32.27 & 30.80 & 27.64 & 30.82 \\
Maicillo & - & 17.49 & 17.04 & 17.46
\end{tabular}

Fuente: Encuesta PERA. Citado en Segundo Perfil de Beneficiarios del Decreto 207. p. 55.

tentación del IRA corresponden a los costos de producción, ya que la realidad no parece corresponder con tal supuesto, cuando menos asi se sostiene en documentos oficiales: "Al hacer un análisis de los costos de producción y los rendimientos promedios obtenidos en los últimos tres afios, se observa que los costos de un quintal de cualquiera de los granos básicos, excepto arroz, está por encima de los precios de garantía que el IRA ha establecido; ello implica que el agricultor con tales precio incurre en pérdidas". 52

Tal realidad exige de ciertas reflexiones: primero un hecho que pudiera parecer curioso es que el único producto para el cual el IRA ofrece un precio superior al costo de producción, cual es el arroz, únicamente

\section{Cuadro 3}

Comparación entre precios de compra del IRA y costo de producción de granos básicos. Cosecha 1983/84

\section{(Datos en \& por qq)}

\begin{tabular}{lcc}
\hline & Preclos del IRA & Costo de Producclón \\
\hline Maiz & 30.00 & 39.89 \\
Maicillo & - & 59.73 \\
Frijol & 80.00 & 102.72 \\
Arroz & 37.00 & 29.45 \\
\hline
\end{tabular}

Fuente: Polltica Nacional de Producción (Area granos básicos y alimentos), San Salvador, mayo 1986. p. 64. 
representa el $3.37 \%$ de la superficie cultivada de granos básicos y el $4.69 \%$ del valor bruto de la producción total efectuada por los beneficios del decreto 20753 . Pero lo curioso se esfuma al reparar en que este cultivo exige de cierto tipo de tierras y de una tecnologia que no es propia del PANC, así tenemos que según el Censo Agropecuario de 1971 , el $53.87 \%$ de la producción de arroz era efectuada en explotaciones de 10 y más has., las cuales, en general, hemos identificado por exclusión como explotaciones capitalistas, y es sabido que el capital no opera si no es con ganancias. Pero además de lo anterior, las explotaciones de100 y más has. que no dejan lugar a dudas de que se trate de auténticas explotaciones capitalistas producian en 1971 el $27.45 \%$ de la producción total54, lo cual de mantenerse actualmente, 0 en todo caso para aquel momento, daria lugar a un fenómeno interesante, cual es que el precio de garantía que fija el IRA beneficia tan sólo a aquellas producciones de elevada productividad, para las cuales sus costos medios son muchísimo menores, esto es, a la producción agrícola capitalista. Por tanto, la existencia de la PANC estaría convirtiéndose en un instrumento para la valorización extraordinaria del capital agricola invertido en la producción de arroz, al ser ella la justificación para la participación del Estado en el establecimiento de un precio de garantía para el arroz que sólo beneficia a la explotación capitalista con elevada productividad.

Una segunda consideración que exige el párrafo citado es lo relativo a las "pérdidas", categoria que presupone la de ganancias o de ingreso neto como es usado en documentos oficiales. Nos parece que tratándose de la producción no capitalista en general el uso de las categorias pérdidas o ganancias no expresan la realidad de los fenómenos que se pretende explicar.

En cuanto a la categoria de ingreso neto que pudiera ser adecuada, a menudo no se tiene en cuenta en su cálculo, aquellos costos que no por haberse dejado de pagar en efectivo, dejan de ser reales. Asi por ejemplo no se considera: el trabajo no remunerado, lo que habriase pagado en concepto de renta, desgaste de instrumentos de trabajo, etc. Todo ello conduce a que en el caso de los beneficiarios del 207, se reporte un ingreso neto anual por familia de $\$ 1.248 .00$, proveniente de su producción ${ }^{55}$. El cual, al profundizar en el estudio de como se llegó a él, se nos revela como falso.

Analicemos los datos reportados en el Segundo Perfil de los Beneficiarios del Decreto $207^{56}$.
Valor Bruto de la Producción (VBP)
Gastos efectivos de producción
Ingreso neto total

$\$ 132.728 .302 .00$
$\$ 51.842 .000 .00$
$\star \quad 80,886.298 .00$ 
Luego ajustan el ingreso neto restándole parte de la produccuión que servirá de semilla y tienen asi un ingreso neto de $₫ 79.428 .974 .00$.

Desglocemos el primer rubro: 57

\begin{tabular}{lrrr}
\hline & $\begin{array}{c}\text { VBP } \\
\text { (Miles de }\end{array}$ & $\begin{array}{c}\text { Producción } \\
\text { (qq) }\end{array}$ & $\begin{array}{c}\text { Superflcie Cultivada } \\
\text { (Mz) }\end{array}$ \\
\hline Maiz & 56.695 .8 & 2.256 .755 & 81.410 \\
Frijol & 20.858 .0 & 348.785 & 30.908 \\
Arroz & 6.214 .7 & 202.917 & 5.234 \\
Maicillo & 11.488 .7 & 615.614 & 37.609 \\
Otros* $^{*}$ & 37.471 .1 & - & 19.918 \\
\hline \multicolumn{1}{c}{ Total } & 132.728 .302 & & 175.079 \\
\hline
\end{tabular}

•Incluye: hortalizas, cáfe, caña, ajonjoll y frutales.

Observemos que en el $11.38 \%$ de la superficie cultivada correspondiente a "otros cultivos" se genera el $28.23 \%$ del VBP. Desafortunadamente el rubro gastos efectivos no aparece desglozado por producto, de alli que conservadoramente podriamos suponer que a los "otros productos" corresponde un $15 \%$ del total de gastos efectivos, sin incluir la semilla. Tendríamos asi aislados los granos básicos que son los que nos interesa analizar.

\begin{tabular}{lccc}
\hline & $\begin{array}{c}\text { (1) } \\
\text { VBP } \\
\text { (Miles de } 4)\end{array}$ & $\begin{array}{c}\text { (1) } \\
\text { Gastos efectivos } \\
\text { (Miles de } 4)\end{array}$ & $\begin{array}{c}(3=1-1) \\
\text { Ingreso neto } \\
\text { (Miles de } 4)\end{array}$ \\
\hline Granos básicos & 95.257 .2 & 44.065 .7 & 51.191 .5 \\
\hline
\end{tabular}

Tal seria aproximadamente el resultado a que se llega a partir de los datos oficiales.

Consideremos ahora los costos reales que implica sólo el cultivo de las $81.410 \mathrm{Mz}$ de maiz. Para ello acudamos a los reportes efectuados por la Dirección General de Economia Agropecuaria, en ellos encontraremos que para la cosecha de 1983/84 el costo promedio por manzana cultivada de maíz fue de $\varnothing 1.182 .42$. Al multiplicar tal cifra por el total de manzanas cultivadas obtenemos una cifra de $\$ 96.264 .883 .00$ que supera en mucho los gastos efectivos, e incluso del VBP del conjunto de granos básicos. 
Si efectuamos los cálculos respectivos para el frijol, arroz y maicillo, cuyos costos de producción reportados por la misma fuente, son respectivamente: $\$ 1.317 .76, \$ 1.639 .73$ y $\$ 1.143 .6958$, obtenemos un costo real de producción para el conjunto de granos básicos de $\$ 188.547 .825 .00$. Cifra que supera al VBP, incluyendo los otros cultivos. Con lo cual, el pretendido ingreso neto estimado por los técnicos responsables del "Segundo Perfil", sencillamente se esfuma. Pero no seamos tan drásticos y supongamos que no se incurrió en ningún costo en el cutlivo del maicillo, dado que éste se efectúa asociado con el maíz. Ello

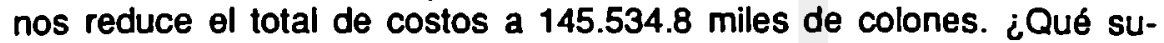
cede? Aún así los costos reales siguen superando al VBP y consiguientemente no puede haber ningún ingreso neto. No puede argumentarse que existe una proporción que se dedica al auto-consumo y que por ello no aparece contabilizada en el VBP, porque claramente lo expresa el Segundo Perfil: "...estimado este último (VBP) en concepto de las ventas y el valor del auto-consumo, resulta una diferencia que se debe a los gastos realizados en semilla para la siembra, que es propia del beneficiario"59. O sea que el VBP, comprende: ventas, el auto-consumo y el costo de la semilla propia.

De todo ello, una cosa debe de quedar clara y ésta es que el ingreso neto, estimado para los beneficiarios del decreto 207, no existe. Es tan sólo una ilusión contable, fruto de considerar tan sólo los gastos efectivos. Ciertamente, el PANC no se paga a si mismo y a su familia un salario; no obstante para efectuar cualquier proceso de trabajo además de medios de producción se requieren medios de vida y esos medios de vida tienen un costo que, necesariamente, debe de ser considerado. Al no tenerlo en cuenta, al igual que otros costos reales, aparece el fetichismo del ingreso neto, que sirve para ocultar la expoliación propia de los productores no capitalistas, la cual evidencia el carácter indirectamente subsumido de sus procesos de trabajo en el capital.

Si contrastamos el VBP por manzana para el maíz, frijol, arroz y maicillo con sus respectivos costos de producción reales por manzana, observaremos la magnitud de la expoliación de que son objeto los beneficiarios del decreto 207.

La columna del total nos muestra el monto de valor expresado en colones que transfirieron los beneficiarios del 207, por cada uno de los productos y la suma de los mismos, durante la cosecha de 1983/84.

Podriamos también suponer que no incurrieron en ningún costo en el cultivo del maicillo y restarle a la transferencia del maiz, el VBP del maicillo. Hecho lo anterior obtendriamos: $₫ 63.833 .467 .00$, cifra qe no deja de ser considerable; aunque sabemos que es exagerado el supuesto efectuado, ya que cuando menos fuerza de trabajo y semilla fue requerida. 
Cuadro 4

Magnitud de la expollación

\begin{tabular}{|c|c|c|c|c|}
\hline & $\begin{array}{l}\text { VeP } \\
(c)\end{array}$ & $\begin{array}{l}\text { Costo de Producclón } \\
\text { ( }(\text { por Mt) }\end{array}$ & $\begin{array}{l}\text { Dlferencla } \\
\text { ( } \text { por Mz) }\end{array}$ & $\begin{array}{l}\text { Total* } \\
(\epsilon)\end{array}$ \\
\hline Malz & 696.42 & 1.182 .47 & -486.05 & 39.569 .331 .00 \\
\hline Frijol & 674.84 & 1.317 .36 & -642.52 & 19.859 .008 .00 \\
\hline Arroz & 1.187 .37 & 1.639 .73 & -452.73 & 2.369.588.00 \\
\hline Maicillo & 305.48 & 1.143 .69 & -838.21 & 31.524 .240 .00 \\
\hline
\end{tabular}

Total

75.322.167.00

Fuente: Estimado a partir de datos del Segundo Perfil de Beneficiarios del 207 y Dirección General de Economla Agropecuaria.

- Número de mz. cultivadas por el diferencial negativo.

Como se ha podido observar el fenómeno es mucho más complejo que una simple pérdida, se trata de una auténtica expoliación, que si bien tiene de común con la explotación el hecho de que haya una expropiación de valor, no se confunde, ni debe de ser confundida con ella, por que se trata de fenómenos diferentes. En la expoliación el capital, o sus personificaciones, los capitalistas no aparecen en escena generalmente, no mantienen relaciones directas con los productores y en todo caso no median relaciones salariales. El productor vende sus productos, sus mercancias $y$, aparentemente, en tal hecho no hay nada irregular. Pero ya hemos visto para los beneficiarios del 207 y durante un año determinado que si son expoliados. Tendremos ocasión de mostrar el mismo fenómeno para los PANC de granos básicos en general y durante varios afios. Por ahora, existen otros elementos que es preciso considerar a fin de lograr una mejor explicación de la relación de subsunción indirecta que se da entre los procesos de trabajo de los beneficiarios del decreto 207 y el capital como un todo.

\section{c.3.3. El Estado, poslbllitante de la expollación del PANC de granos básicos}

Ya hemos señalado como el Estado posibilita la existencia de los PANC de granos básicos, el decreto 207 es su obra. En el pasado se buscó fomentar su existencia a través de una institución denominada Administración de Bienestar Campesino (ABC), la cual posibilitó la adquisición de algunas tierras, brindó algún crédito y también asistencia técnica. La participación del Estado no es un fenómeno nuevo. Pero en este apartado nos interesa develar cómo el Estado se convierte en un instrumento posibilitante de la expoliación. El Estado, a través del IRA, 
busca mantener bajos los precios de los granos básicos, lo cual contribuye a mantener bajos los salarios obreros. Ello se traduce en menores costos para el capital, posibilitando asi una valorización extraordinaria del mismo. No se trata del mecanismo de la plusvalía relativa en tanto los salarios se mantienen comprimidos, no debido a un valor bajo de la fuerza de trabajo originado en una disminución del valor de sus medios de vida, sino en una adquisición de los mismos por debajo de su valor, gracias a la expoliación de que son objeto los productores no capitalistas en general y los PANC de granos básicos en particular, dentro de ellos, los beneficiarios del 207.

Pero bien, veamos cómo actúa el Estado. Este al fijar los precios de garantia para el productor, que como ya veiamos no cubren los costos de producción, lo que está haciendo de hecho es fijar un precio máximo de compra al productor y en tanto, compra una porción mínima de la producción, el productor se ve obligado a venderle al comerciante-transportista a precios inferiores que los fijados por el Estado. La consecuencia de elllo es que el nivel de precios de los granos básciso, no está acorde con el nivel general de precios. (Vease el Cuadro No. 5).

Los datos muestran claramente que la tendencia es que los precios de los granos básicos vayan a la zaga del nivel general de precios, ya sea a nivel de productor como a nivel de consumidor, lo cual está evidenciando el papel del Estado, a través del IRA, como posibilitante de la expoliación del PANC de granos básicos y dentro de ellos los beneficiarios del 207, que como ya veíamos su principal producción es de granos básicos y su aporte a la producción nacional también es significativo.

También se observa que el mayor indice lo presenta el maicillo, lo cual viene a confirmar que la intervención del Estado si cuenta, en tanto que para este producto el Estado no tiene precios de garantia.

Por otra parte, también resulta interesante observar que los índices de precios al consumidor han evolucionado menos que los precios al productor, lo cual viene también a re-afirmar que el Estado, aunque comercialice una pequeña proporción de la oferta de granos básicos, si incide en sus precios.

Todo ello, viene a confirmar nuestra tesis de que el Estado es un instrumento posibilitante de la subsunción indirecta de los procesos de trabajo de los PANC de granos báscos en el capital. Lo cual lo hemos observado a través de sus acciones tendientes a tomentar la existencia de los PANC y por otra parte, en tanto que posibilita su expoliación mediante su intervención en la determinación de los precios, todo to cual contribuye a una valorización extraordinaria del capital. 


\section{Cuadro 5}

Comparación entre la evolución de precios de granos básicos y

el Indice de Precios al Consumidor Obrero (IPCO)

\begin{tabular}{|c|c|c|c|c|c|c|c|c|c|}
\hline & \multicolumn{4}{|c|}{$\begin{array}{l}\text { Indice de precios granos básicos }(1) \\
\quad(\text { Año base } 1978=100)\end{array}$} & \multirow{2}{*}{\multicolumn{2}{|c|}{ 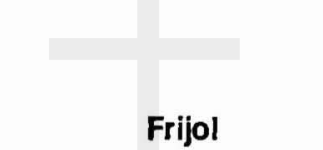 }} & & & \multirow{3}{*}{$\begin{array}{l}\text { IPCO (2) } \\
\text { (Base Dlc. } \\
1978=100\end{array}$} \\
\hline & \multirow[b]{2}{*}{ Productor } & \multirow{2}{*}{$\begin{array}{l}\text { Malz } \\
\text { Consumldor }\end{array}$} & \multicolumn{2}{|c|}{ Maicillo } & & & \multicolumn{2}{|c|}{ Arroz" } & \\
\hline & & & Product. & Consum. & Product. & $\begin{array}{l}\text { Frijol } \\
\text { Consum. }\end{array}$ & $\begin{array}{l}\text { Cons. de } \\
\text { 1a. }\end{array}$ & $\begin{array}{l}\text { Cons. de } \\
2 a \text {. }\end{array}$ & \\
\hline 1978 & 100.0 & 100.0 & 100.0 & 100.0 & 100.0 & 100.0 & 100.0 & 100.0 & 100.0 \\
\hline 1979 & 74.6 & 82.8 & 100.0 & 100.0 & 78.4 & 83.3 & 86.3 & 92.1 & 108.7 \\
\hline 1980 & 85.0 & 89.7 & 114.0 & 104.3 & 150.3 & 141.0 & 89.0 & 95.2 & 127.6 \\
\hline 1981 & 95.9 & 96.6 & 128.7 & 121.7 & 145.7 & 146.2 & 95.9 & 101.6 & 146.4 \\
\hline 1982 & 94.0 & 100.0 & 125.6 & 121.7 & 120.8 & 126.9 & 97.3 & 117.7 & 163.6 \\
\hline 1983 & 105.0 & 117.2 & 134.1 & 139.1 & 97.4 & 109.0 & 120.5 & 127.0 & 185.1 \\
\hline 1984 & 109.0 & 120.7 & 128.6 & 113.0 & 88.7 & 102.6 & 123.3 & 127.0 & 206.7 \\
\hline 1985 & 103.5 & 106.9 & 133.0 & 139.1 & 111.1 & 120.5 & 108.2 & 117.5 & 252.9 \\
\hline 1986 & 151.5 & 141.4 & 223.5 & 182.6 & 167.4 & 160.3 & 116.4 & 122.2 & $333.6(3)$ \\
\hline
\end{tabular}

Fuenle: (1) Estimados a partir de información de la Dirección General de Economla Agropecuaria. MAG.

(2) Indicadores Económicos y Sociales. MIPLAN.

(3) banco Central de Reserva de El Salvador.

- No logramos datos a nivel de produclor. Además los Indices presentados son para el arroz ya beneficiado. 


\section{d. Visión sintética del apartado}

En general nos parece haber logrado mostrar suficientemente:

Primero, que los beneficiarios del decreto 207, o tercera fase de la Reforma Agraria, constituyen una muestra típica del PANC de granos básicos;

Segundo, que sus procesos de trabajo en tanto actúan como PANC se encuentran subsumidos indirectamente en el capital;

Tercero, que tal subsunción ha sido constatada:

1- Al mostrar que la PANC de granos básicos existe en tanto resulta útil y necesaria al capital y siendo que los beneficiarios del decreto 207 se dedican fundamentalmente a la producción de granos básicos, su existencia responde a la lógica del capital.

2- Al producir mayoritariamente granos básicos, a los beneficiarios del decreto 207 se les posibilita la auto-reproducción parcial de su fuerza de trabajo, lo cual exige y a su vez posibilita la venta de la misma por debajo de su valor, constituyendose asi sus procesos de trabajo, en tanto PANC, en instrumento de valorización extraordinaria del capital. Además en tanto se da una auto-reproducción parcial de la fuerza de trabajo mediante la PANC de granos básicos, tal producción se convierte en vivero de fuerza de trabajo joven; en refugio temporal mientras el capital no reclame a la fuerza de trabajo; y en asilo permanente, cuando el capital ya no la requiere.

3- Al producir una parte significativa de la alimentación de la clase trabajadora y realizarla a precios que no cubren sus costos reales de producción, contribuyen a mantener "barata" la fuerza de trabajo asalariada, posibilitando asi disminuir los costos del capital y consiguientemente convirtiéndose sus procesos de trabajo en instrumentos indirectos de valorización del capital.

4- Al mostrar, aunque sea en forma aproximada, la magnitud de la expoliación que experimentan los beneficiarios del decreto 207, develamos asi el fetichismo del ingreso neto que reportan los documentos oficiales para los beneficiarios del decreto 207.

Cuarto, adicionalmente se presenta el papel del Estado en tanto promotor de la existencia de la PANC de granos básicos y en tanto posibilitante de su expoliación.

III. Evidencla adiclonal acerca del carácter Indirectamente subsumido de los procesos de trabajo de los PANC de granos básicos en el capital.

Nos parece que el carácter indirectamente subsumido de los pro- 
cesos de trabajo de los PANC beneficiarios del decreto 207 en el capital, ha sido suficientemente evidenciado.

Quisiéramos ahora presentar algunos indicadores de la subsunción indirecta para los PANC de granos básicos en general:

a. Relaciones de intercambio entre los PANC de granos básicos y el capital.

Para 1986, el índice de precios del maiz fue de 151.5, el del maicillo de 233.5 y del frijol de 167.4 ; del total de quintales producidos, el $73 \%$ corresponde a maiz, el $20 \%$ a maicillo y el $7 \%$ a frijol, aproximadamente, y si tenemos en cuenta que la productividad media para los tres productos no se ha incrementado, resulta que el índice de precios promedio ponderado para los tres productos es de 167.0, el cual al ser comparado con el indice de precios al consumidor obrero, para 1986 que fue 333.6, nos está indicando que los precios de los granos básicos a nivel de productor, apenas corresponden al $50 \%$ de los precios de aquellos productos que, en su gran mayoria, demandan los PANC de granos básicos (Véase cuadro $A$ y $B$ en el anexo).

Las implicaciones que de ello se desprenden es posible mostrarlas a través de un sencillo ejercicio: seleccionamos un grupo de artículos que son producidos en forma capitalista y además que son consumidos por los PANC; luego comparamos sus precios para 1978 y 1985 con los de los granos básicos. Tomamos 1978 por ser el año que ha servido de base para numerosos estudios y 1985; por ser el último afio para el cual encontramos precios por producto.

\section{Cuadro 6 \\ Preclos al por menor de algunos articulos de consumo popular (Preclos en $६$ )}

\begin{tabular}{llc}
\hline & 1978 & 1985 \\
\hline 1 Bola de jabón para lavar & 0.54 & 1.37 \\
1 Botella de kerosone & 0.33 & 1.00 \\
1 Caja de fósforos & 0.10 & 0.25 \\
1 Libra de velas & 1.33 & 3.95 \\
1 Refresco gaseoso & 0.20 & 0.75 \\
1 Libra de macarrones & 1.33 & 2.75 \\
1 Libra de café molido de 2da. & 4.63 & 4.58 \\
1 Botela de aceite vegetal & 1.49 & 2.41 \\
1 Libra de margarina & 1.66 & 3.24 \\
1 Libra de pescado seco & 1.54 & 6.61 \\
\hline Total & 13.65 & 28.36 \\
\hline
\end{tabular}

Fuente: Indicadores económicos y sociales, enero-diciembre 1985. 
Claramente se observa como los precios que reciben los PANC de granos básicos por sus mercancias no se ajustan a los precios que tienen que pagar por los artículos para su consumo. En el Cuadro No. 8, se manifiesta con mucha mayor claridad tal situación. Observamos como el PANC tiene que entregar en 1985 una mayor cantidad de maiz, de maicillo o de frijol para poder adquirir la misma cantidad de productos que adquiría en 1978.

\section{Cuadro 7 \\ Precios comparativos de granos básicos a nivel de productor ( $\$$ por qq)}

\begin{tabular}{lll}
\hline & 1978 & 1985 \\
\hline Maiz & 20.54 & 20.80 \\
Maicillo & 13.92 & 17.20 \\
Frijol & 55.53 & 62.40 \\
\hline
\end{tabular}

Fuente: Dirección General de Economía Agropecuaria. MAG.

\section{Cuadro 8}

Cantldad en términos físicos para adquirir el conjunto de articulos seleccionados

\begin{tabular}{lll}
\hline & 1978 & 1985 \\
\hline Maiz & $0.66 \mathrm{qq}$. & $1.36 \mathrm{qq}$. \\
Maicillo & $0.98 \mathrm{qq}$. & 1.65 qq. \\
Frijol & $0.25 \mathrm{qq}$. & $0.45 \mathrm{qq}$. \\
\hline
\end{tabular}

Fuente: Datos estimados a partir de cuadros anteriores.

O visto lo anterior en términos mucho más simples, si en 1978 una bola de jabón para lavar costaba al PANC: 2 1/2 libras de maiz, en 1985 por la misma bola tenia que entregar a cambio $61 / 2$ libras de maiz.

Al no ajustarse los precios de los granos básicos al nivel general de precios, el PANC de granos básicos ve deteriorarse su capacidad adquisitiva de aquellos otros medios de vida que requiere para su reproducción material. Pero a su vez lo anterior nos está indicando también que a través de este intercambio desigual se da una transferencia de valor desde los PANC de granos básicos hacia el capital, hacia los sectores capitalistas de la economia. Por lo cual sus procesos de trabajo se 
convierten en instrumentos indirectos de valorización extraordinaria de capital. Por tanto, sus procesos de trabajo se encuentran indirectamente subsumidos en el capital. Aunque a nivel de apariencia pareciera ser que quienes expolian a los PANC de granos básicos son los consumidores. Pero bien mirado el fenómeno, descubrimos que esos consumidores no son más que asalariados del capital, en su gran mayoria, y por tanto quien se ve favorecido en última instancia es el capital, al no tener que incrementar sus costos via aumentos en los salarios.

Finalmente hay una porción del maiz y del maicillo que entra como materia prima en la producción industrial de concentrados y harinas.

Para 1984/85 el consumo industrial de maíz tue el $22.3 \%$ del consumo humano y el del maicillo represento el $63.5 \%$ del total destinado al consumo humano. En términos absolutos: 93,624 y 37.789 toneladas métricas, respectivamente ${ }^{60}$. Lo cual, nos está indicando que el mantener los términos de intercambio desfavorables al PANC de granos básicos también beneficia directamente al capital industrial, sin que medie una relación directa entre el capital y la fuerza de trabajo de los PANC. Ellos venden sus mercancías por unos precios que no controlan, y en esa medida éstos avanzan muy rezagados tras el nivel general de precios. A menudo se hace responsable de tal situación a los intermediarios-transportistas, sin embargo cuando veiamos este fenómeno en términos teóricos no compartiamos tal apreciación. Veamos en ejemplo numérico que nos ilustre. Un intermediario-transportistas posee un camión de 5 toneladas y compra 100 qq de maiz por \$2.190.00 y los vende por $\$ 2.850 .00$ a una fábrica de concentrados y obtiene una diferencia de $\$ 660.00$. Pero de ello es preciso restar: pago de 3 mozos, del motorista, del combustible, desgaste de llantas, mantenimiento del vehículo y depreciación del mismo, gastos extraordinarios, etc. Interés por el dinero empleado ya sea propio o prestado y remuneración por su trabajo. ¿Realmente se puede sostener en forma razonable que es el intermediario-transportista el responsable de la expoliación del PANC de granos básicos? ¿O por el contrario lo es el industrial capitalista quien fija el precio de compra al intermediario transportista? En primer lugar, siendo que el transporte es una prolongación de la producción, en tal actividad hay una generación de valor, de allí que cualquiera que fuese el precio pagado al PANC de granos básicos, siempre se vería incrementado luego de ser transportado hacia el lugar necesario para su consumo. Segundo, al ser el industrial quien fija el precio de compra al intermediariotransportista, de hecho está determinando el precio para el PANC. Esto es valido ya sea que se trate del maíz o del maicillo, ya que en la comercialización de este producto no interviene el Estado y además el volumen demandado por el capital industrial representa una mayor proporción del consumo humano. No obstante, para el caso del maiz, lo 
dicho respecto al Estado no se invalida, ya que éste con su acción lo que hace es establecer precios máximos pero no los minimos, que son los que recibe el PANC.

Por tanto, nos parece que también a través de esta relación mediada por el comerciante-transportista se da una expoliación del PANC por parte del capital industrial, que logra una valorización extraordinaria, al comprar materias primas a precios que están por debajo de su valor. Lo cual, nos está indicando un mecanismo adicional de subsunción indirecta de los procesos de trabajo de los PANC de granos básicos en el capital.

Iniciábamos este apartado con la demanda de medios de vida que efectúa el PANC y veíamos cómo es expoliado por esta vía, luego complementamos lo anterior con el otro lado de la relación: la demanda de sus productos por parte de los consumidores y por el capital industrial, encontrando en este último lo que teóricamente consideramos como casos particulares de subsunción indirecta. Ello es asi, por que la subsunción indirecta del trabajo no se da en el capital como un todo sino en determinados capitales.

Para completar este cuadro nos haria falta estudiar la demanda de insumos que efectúa ol PANC, pero antes de proceder a ello es necesario hacer algunas consideraciones de carácter cualitativo sobre la demanda de medios de vida y medios de producción, que sin ser exclusiva de los PANC de granos básicos, si les ataf́e en tanto son parte integrante del conjunto de demandantes.

A medida que ha ido desarrollándose la producción capitalista su influencia se ha hecho sentir en distintos ámbitos, uno de los cuales es la detemrinación del consumo de medios de vida y de producción de los PANC. Sus patrones de consumo han sido modificados sustancialmente con diferentes efectos, entre los cuales nos interesa destacar: el rompimiento de las relaciones funcionales entre los diferentes productores no capitalistas en general y la subordinación al mercado capitalista experimentada por los PANC, con lo cual se profundizan aún más sus relaciones de expoliación a través del intercambio desigual.

En cuanto a los medios de vida podemos sefialar brevemente a algunos de ellos: el azúcar refinada sustituye al dulce de atado, el calzado de hule o de plástico sustituye al calzado de cuero y/o al caite, las telas sintéticas sustituyen a las telas de algodón; utensilios de plástico o de aluminio en sustitución de utensilios de barro, sombreros de plástico en sustitución de sombreros de palma, etc.; en cuanto a los medios de producción, tenemos el uso de híbridos en sustitución de semillas criollas, el uso de fertilizantes químicos en sustitución de fertilizantes naturales, el uso de herbicidas e insecticidas, el uso de transporte mecánico en vez del transporte animal, y en general el uso de instrumentos 
de trabajo producidos bajo formas capitalistas, tales como: el machete, la cuma, el pico, el azadón, carretillas, arados, etc. en sustitución de los producidos por los PMNC. (Productores Manufactureros no Capitalistas).

La enumeración anterior más que exhaustiva pretende ser ilustrativa, a fin de mostrar cómo al modificarse la demanda de mercancias producidas bajo formas no capitalistas se pasa a depender del mercado capitallsta, sobre cuyos precios el PANC no posee ningún control, a diferencia de las relaciones funcionales que se presentaban entre productores no capitalistas. Decimos funcionales en tanto que la existencia de los mismos estaba determinada mutuamente; lo cual era un limite para que se operase un intercambio entre no equivalentes. Cosa muy diferente ocurre con las relaciones entre el PANC y el capital, las cuales se caracterizan por la expoliación dado el carácter indirectamente subsumido que presentan sus procesos de trabajo en el capital.

Pero además al modificar la producción capitalista el consumo personal o productivo de los PANC y quebrar las relaciones funcionales entre los productores no capitalistas, se opera un proceso de subordinación de los mismos al capital, en tanto ya no pueden prescindir de las mercancias capitalisticamente producidas, y a su vez, se operan modificaciones en el proceso mismo de trabajo de los PANC. El uso, por ejemplo, de herbicidas sustituye al machete por la bomba de aspersión en el deshierbe, lo cual introduce un nuevo elemento de dependencia del mercado capitalista. Lo mismo puede decirse del uso de hidridos, que exige no sólo la compra de semilla en el mercado capitalista, sino a su vez el empleo de determinadas dosis de fertilizantes químicos en ciertos momentos precisos. A la par con la introducción de semillas mejoradas y fertilizantes químicos, van operándose modificaciones en las prácticas culturales: la tala y quema pasa a ser cosa del pasado. $Y$ si bien ello redunda en la conservación de la fertilidad del suelo, exige a su vez, el control de plagas del suelo y del follaje, por lo que el uso de insecticidas se vuelve indispensable en la producción de granos básicos a fin de lograr una producción satisfactoria.

Para darnos una mejor idea de la llamada penetración tecnológica en el cultivo de granos básicos, presentamos a continuación algunos datos: el $15 \%$ de los productores utiliza maquinaria en la preparación del suelo, el $65 \%$ usa semilla mejorada, el $100 \%$ usa fertilizantes químicos, aunque en su gran mayoria lo haga en dosis inadecuadas, el $40 \%$ usa insecticidas y el $70 \%$ aplican herbicidas. 61

Los datos anteriores muestran que el empleo de semillas mejoradas, fertilizantes $\theta$ insecticidas son un hecho real en la PANC, por lo cual las aseveraciones efectuadas respecto a su carácter subordinado al capital tienen su fundamento en la propia práctica de estos productores. Por 
tanto, también desde esta otra perspectiva es posible observar el carácter indirectamente subsumido de sus procesos de trabajo en el capital.

Procederemos ahora a estudiar las relaciones que se dan entre los PANC y el capital, a través de la demanda de insumos. Nos interesa evidenciar cómo esta relación también constituye un mecanismo de transferencia de valor por parte de los PANC. Para ello procederemos a comparar los índices de precisos de los granos básicos y de los insumos. Tomando como base el año de 1978, tenemos para 1986 los siguientes datos:

\section{Cuadro 9}

Indlces de preclos de granos y de sus Insumos para cosecha 1986/1987

\begin{tabular}{lcc}
\hline & $\begin{array}{c}\text { Indice de preclos } \\
\text { a nlvel de productor }\end{array}$ & $\begin{array}{c}\text { Indlce de precios de } \\
\text { los slnumos respectlvos* }\end{array}$ \\
\hline Maiz & 151.5 & 315.9 \\
Maicillo & 223.5 & 525.0 \\
Frijol & 167.4 & 301.1 \\
\hline
\end{tabular}

Fuente: Véase Cuadros A yn C al final del capltulo.

- Comprende: semilla, fertilizante sy pesticidas.

Lo cual claramente evidencias - si recordamos que no se dan incrementos en la productividad-cómo a través de la compra de insumos el PANC de granos básicos también es expoliado. El diferencial entre ambos índices es evidente. Pero a fin de que resulte aún más obvio examinaremos algunos productos en particular.

Cuadro 10

Comparación de preclos de Insumos

\begin{tabular}{lrr}
\hline & 1978 & 1986 \\
\hline Sulfato de amonio $100 \mathrm{Kg}$. & 32.00 & 83.00 \\
Fórmula 16-20-0 100 Kg. & 46.00 & 130.00 \\
Dipterex Kg. & 13.80 & 43.80 \\
Tamaron 600 litro & 24.80 & 54.00 \\
\hline Total & 116.60 & 310.00 \\
\hline
\end{tabular}

Fuente: Dirección General de Economia Agropecuaria. MAG. 
Para adquirir esas cantidades de agro-quimicos el productor debia de entregar en términos de maíz, maicillo y frijol, las siguientes cantidades:

1978

$\begin{array}{llr}\text { Maiz } & 5.8 \mathrm{qq} . & 10.2 \mathrm{qq} . \\ \text { Maicillo } & 9.0 \mathrm{qq} . & 10.8 \mathrm{qq} . \\ \text { Frijol } & 2.0 \mathrm{qq} . & 3.3 \mathrm{qq} .\end{array}$

1986

$$
\begin{array}{r}
10.2 \mathrm{qq} . \\
10.8 \mathrm{qq} . \\
3.3 \mathrm{qq}
\end{array}
$$

Resulta obvia la evolución desfavorable en los términos de intercambio. Pero veámosla en forma más sencilla aún, si en 1978 para adquirir un saco de $100 \mathrm{Kg}$. de fórmula el PANC debia de entregar $21 / 4 \mathrm{qq}$ de maíz, en 1986 por la misma cantidad del mismo producto debe dar a cambio $41 / 4$ qq de maiz. Tales relaciones de intercambio, ciertamente, lo que hacen es que el PANC tiene que transferir cada vez una mayor cantidad de valor creado en sus procesos de trabajo hacia los sectores capitalistas nacionales $y / 0$ extranjeros.

La afectación de los PANC por el incremento de los precios de los insumos, incluida la semilla, resulta también evidenciada al constatar que, para el caso del maiz, pasan de contormar el $24.8 \%$ de los costos de producción en 1978 a un $33.4 \%$ en 1986; en el caso del maicillo pasan de $16.0 \%$ a $27.7 \%$; y en el frijol pasan de $26.6 \%$ a $35.0 \% .62$ Teniendo obviamente una incidencia considerable en el incremento de los costos de producción. Pero estos últimos preferimos estudiarlos en un apartado especial.

\section{b. Relaclón entre Ingresos y costos de producción de los PANC de granos básicos: maiz, maicllio y trljol}

A lo largo de este trabajo, referido a la PANC de granos básicos hemos sostenido una y otra vez que estos productores venden sus mercancias a precios inferiores a sus costos de producción, sin embargo, nos parece que es preciso estudiar con más detalle tanto los costos como los ingresos de los PANC de granos básicos, y a la vez mostrar como la constante transferencia de valor por parte de los productores de granos básicos nos confirma el carácter crónico de la subsunción indirecta de sus procesos de trabajo en el capital, asi como explicar también: por qué y cómo, ello es posible. Igualmente mostrar que en esas condiciones la renta de la tierra y los intereses, se convierten en mecanismos adicionales de expoliación.

Partiendo del mismo año base que hemos venido utilizando, mostremos rápidamente y en forma esquemática la relación entre los índices de precios a nivel de productor y los costos de producción para el año de 1986 (véase cuadros A y D del anexo). 


$\begin{array}{lll}\text { Maiz } & 151.5 & 235.2 \\ \text { Maicillo } & 223.5 & 302.8 \\ \text { Frijol } & 167.4 & 228.8\end{array}$

Es evidente que para cada uno de los productos sus costos se han incrementado mucho más que sus precios. Pero si para el año base los precios hubiesen sido remunerativos tal diferencial no deberia de interpretarse como "maligno" para el PANC, sino como un simple ajuste, o en todo caso, no podría indicarnos más que una simple diferencia. De tal modo que es preciso retrotraernos al año de 1978 y observar la relación ingresos-costos: maiz: - 220.22 colones por manzana, maicillo: -343.13 y frijol: 121.25. Sólo para el caso del trijol y solamente para ese año el PANC de granos básicos obtuvo un diferencial positivo, el resto son negativos. Por tanto, no se trata de un ajuste, ni de una mera diferencia. El retrazo que muestran los precios de los granos básicos con respecto a sus costos es un fenómeno constante. Es por ello que aparece el diferencial negativo que se presenta en el Cuadro No. 11 (para su cálculo véase Cuadros $E, F, G$ y $H$, en el anexo).

Pero estos diferenciales a su vez revelan un fenómeno mucho más interesante, cual es la expoliación que experimentan los PANC. Si observamos en el cuadro anterior el diferencial medio para el periodo, tenemos que por cada manzana que cultivaron los PANC durante esos 9 años, transfirieron un valor expresado en colones de 658.17 cuando fue maíz, de 772.24 cuando fue maicillo y de 362.23 cuando se trató de frijol.

Para tener una mejor idea acerca de la relevancia del fenómeno de la expoliación que experimentan los PANC de granos básicos, es posible estimar que de 1978 a 1986 transfirieron un valor expresado en colones de 2.206.2 millones de colones sólo provenientes del cultivo del maiz. El dato ciertamente es bastante aproximado, ya que suponemos que toda la producción de maiz se efectuó bajo formas no capitalistas $y$, además suponemos costos de producción para maiz hibrido y no toda la producción se efectúa con semilla mejorada, pero si en su gran mayoría. Además de ello, el dato lo obtuvimos a partir de un promedio anual de manzanas cultivadas y un promedio anual de la diferencia entre ingresos y costos. Con todo lo aproximado que es, si está reflejando la existencia del fenómeno de la expoliación, aunque la magnitud de la misma pudiera ser menor. A fin de completar este punto veamos a continuación los datos para los otros productos de que nos hemos venido ucupando (ver Cuadro No. 12).

Adicionalmente hemos calculado la magnitud de la expoliación por producto durante el período de 1978 a 1986. Señalamos en el Cuadro 
Ingresos brutos promedlo menos costos de produccion por manzana cultlvada. (Clifras en colones)

(o transferencla anual por manzana cultivada)

\begin{tabular}{llll}
\hline & Malz & Malclllo & Frljol \\
\hline 1978 & -220.22 & -343.13 & 121.25 \\
1979 & -485.75 & -444.22 & -266.10 \\
1980 & -705.63 & -434.29 & -253.38 \\
1981 & -729.20 & -840.97 & -372.12 \\
1982 & -744.54 & -871.17 & -617.40 \\
1983 & -604.33 & -851.32 & -693.98 \\
1984 & -709.51 & -928.02 & -363.90 \\
1985 & -731.76 & -1.001 .65 & -470.01 \\
1986 & -992.62 & -1.235 .41 & -344.46 \\
$1978-1986$ & -658.17 & -772.24 & -362.23 \\
\hline
\end{tabular}

Fuente: Estimación electuada a partir de información de la Dirección General de Economía Agropecuaria.

\section{Cuadro 12}

\section{Monto aproximado de transferenclas efectuadas} por la PANC en granos básicos durante el período de 1978 a 1986

\begin{tabular}{|c|c|c|c|c|}
\hline & $\begin{array}{l}\text { Transferencla } \\
\text { por maz prome- } \\
\text { dlo perlodo } \\
\text { (colones) }\end{array}$ & $\begin{array}{l}\text { Mzs. } \\
\text { cultlvadas } \\
\text { promedlo } \\
\text { perlodo }\end{array}$ & $\begin{array}{l}\text { Total transf. } \\
\text { anual por } \\
\text { producto } \\
\text { (colones) }\end{array}$ & $\begin{array}{l}\text { Total trans. du- } \\
\text { rante el periodo } \\
\text { por producto } \\
\text { (colones }\end{array}$ \\
\hline $\begin{array}{l}\text { Malz } \\
\text { Maicillo } \\
\text { Frijol }\end{array}$ & $\begin{array}{l}658.17 \\
772.24 \\
362.23\end{array}$ & $\begin{array}{r}372.462 \\
172.900 \\
78.633\end{array}$ & $\begin{array}{r}245.143 .314 .50 \\
133.520 .296 .00 \\
28.483 .231 .59\end{array}$ & $\begin{array}{r}2.206 .289 .831 .00 \\
1.201 .682 .664 .00 \\
256.349 .084 .30\end{array}$ \\
\hline & - & 一 & 407.146 .842 .10 & 3.664 .421 .579 .00 \\
\hline
\end{tabular}

Fuenle: Estimaciones electuadas a partir de datos de la dirección General de Economla Agropecuaria. MAG. 
No. 13 que se trata de datos aproximados debido a muchos supuestos que hemos efectuado, tales como: 1) que los tres productos se cultivan por separado, cuando en realidad una parte se cultiva sola y otra en forma asociada: maiz con maicillo y maiz con frijol. Sin embargo en el caso del frijol la tendencia es a cultivarse solo y lo contario ocurre con el maicillo. 2) Que toda la producción se destina al mercado, cuando en realidad hay una proporción que es autoconsumida por los productores. 3) Además de los previamente señalados.

Teniendo en mente esas aclaraciones que limitan cualquier pretensión de exactitud -que no tenemos, ciertamente- si es posible observar cierta tendencia a que se incremente la expoliación cuando se trata del cultivo del maíz y del maicillo. No asi en el caso del frijol que tendió a elevarse y luego a bajar. Además de ello en este cultivo es donde se observa una menor magnitud de la expoliación promedio para el periodo, lo cual se explica por el comportamiento antes señalado.

Pero bien, más que efectuar una lectura de los cuadros nos importa explicar los saldos negativos que se obtienen al relacionar los ingresos y costos de producción de los granos básicos.

En primer lugar, al observar la estructura de costos que reporta la Dirección General de Economia Agropecuaria, encontramos que se trata de una estructura de costos propia de una explotación capitalista. Tomemos por ejemlo, los costos de producción del maíz en 1978.

Tratándose de una explotación capitalista, ciertamente no podria prescindirse de ninguno de los rubros senalados, incluso, debería de aparecer un rubro por depreciación de maquinaria y equipo. De allí que para continuar produciendo deberia de poseer una productividad por arriba de la media, a fin de recuperar sus costos y obtener una determinada ganancia. Para el año sef́alado los costos por manzana cultivada fueron de $₫ 807.14$ y los ingresos promedio de 586.92 colones por manzana, para el maiz (véase cuadro $\mathrm{G}$ y $\mathrm{H}$ en el anexo).

En segundo lugar, siendo que la producción de maíz, como el frijol y el maicillo, es efectuada mayoritariamente por PANC. Una posible explicación de cómo producen con un diferencial negativo puede encontrarse en la estructura de costos mismos, teniendo en cuenta además de que son propietarios de la tierra - al menos de una parte de la que cultivan- y que generalmente no recurren al crédito, o de hacerlo a menudo no lo obtienen.

De lo anterir resulta que el último subtotal presentado en el Cuadro No. 14 puede ser excluido de los costos, con lo cual éstos se reducirían a c602.13, igualmente puede excluirse el rubro de administración con lo que ya tenemos un costo de $\$ 584.6$ contra un ingreso promedio para 


\section{Cuadro 13}

\section{Expoliación anual de los productores agricolas no capitalistas (PANC)}

de granos básicos. Datos aproximados (totales en miles de $ఢ$ )

\begin{tabular}{|c|c|c|c|c|c|c|c|c|c|}
\hline & \multicolumn{2}{|c|}{ Maiz } & \multirow[b]{2}{*}{ Total } & \multicolumn{2}{|c|}{ Maicillo } & \multicolumn{4}{|c|}{ Frljol } \\
\hline & $\begin{array}{l}\text { Transfe- } \\
\text { rencia por } \\
\text { manzana } \\
\text { cultivada }\end{array}$ & $\begin{array}{l}\text { Total de } \\
\text { manzanas } \\
\text { cultivadas }\end{array}$ & & $\begin{array}{c}\text { Transle- } \\
\text { rencia por } \\
\text { manzana } \\
\text { cultivada }\end{array}$ & $\begin{array}{l}\text { Total de } \\
\text { manzanas } \\
\text { cultivadas }\end{array}$ & Total & $\begin{array}{c}\text { Transfe- } \\
\text { rencla por } \\
\text { manzana } \\
\text { cultivada }\end{array}$ & $\begin{array}{l}\text { Total de } \\
\text { manzanas } \\
\text { cultuvadas }\end{array}$ & Total \\
\hline 1978 & -220.22 & 377.600 & 83.155 .0 & $-\quad 343.13$ & 195.400 & 67.047 .6 & 121.25 & 74.000 & - \\
\hline 1979 & -485.75 & 394.300 & 191.531 .1 & $-\quad 444.22$ & 205.000 & 91.065 .1 & -266.10 & 78.700 & 20.942 .0 \\
\hline 1980 & -705.63 & 417.000 & 294.247 .7 & $-\quad 434.29$ & 170.700 & 74.133 .3 & -253.38 & 75.000 & 19.003 .5 \\
\hline 1981 & -729.20 & 395.000 & 288.034 .0 & - 840.97 & 165.000 & 138.760 .0 & -372.12 & 71.000 & 26.420 .5 \\
\hline 1982 & -744.54 & 341.000 & 253.888 .1 & - 871.17 & 170.000 & 148.098 .9 & -617.40 & 79.400 & 49.021 .5 \\
\hline 1983 & -604.33 & 345.000 & 208.493 .8 & - 851.32 & 158.000 & 134.508 .5 & -693.98 & 80.500 & 55.865 .3 \\
\hline 1984 & -709.51 & 347.700 & 246.696 .6 & -928.03 & 166.000 & 154.052 .9 & -363.90 & 82.500 & 30.021 .7 \\
\hline 1985 & -731.76 & 362.100 & 264.970 .0 & -1.001 .65 & 163.400 & 163.696 .6 & -470.01 & 83.300 & 39.151 .8 \\
\hline 1986 & -992.62 & $362.100^{\circ}$ & 359.427 .7 & 1.235 .41 & $163.400^{*}$ & 201.865 .9 & -344.42 & $83.300^{*}$ & 28.690 .1 \\
\hline $1978-1986$ & -658.17 & $372.462^{* *}$ & & $772.24^{* *}$ & 172.900 & & -362.23 & $78.633^{* *}$ & \\
\hline
\end{tabular}

Fuente: Estimado a partir de información de la Dirección General de Economia Agropecuaria. MAG.

- Suponemos el mismo número de manzanas cultivadas en el año anterior.

- Promedio no incluye el año de 1986. 
costos de producción de $1 \mathrm{Mz}$. de maiz

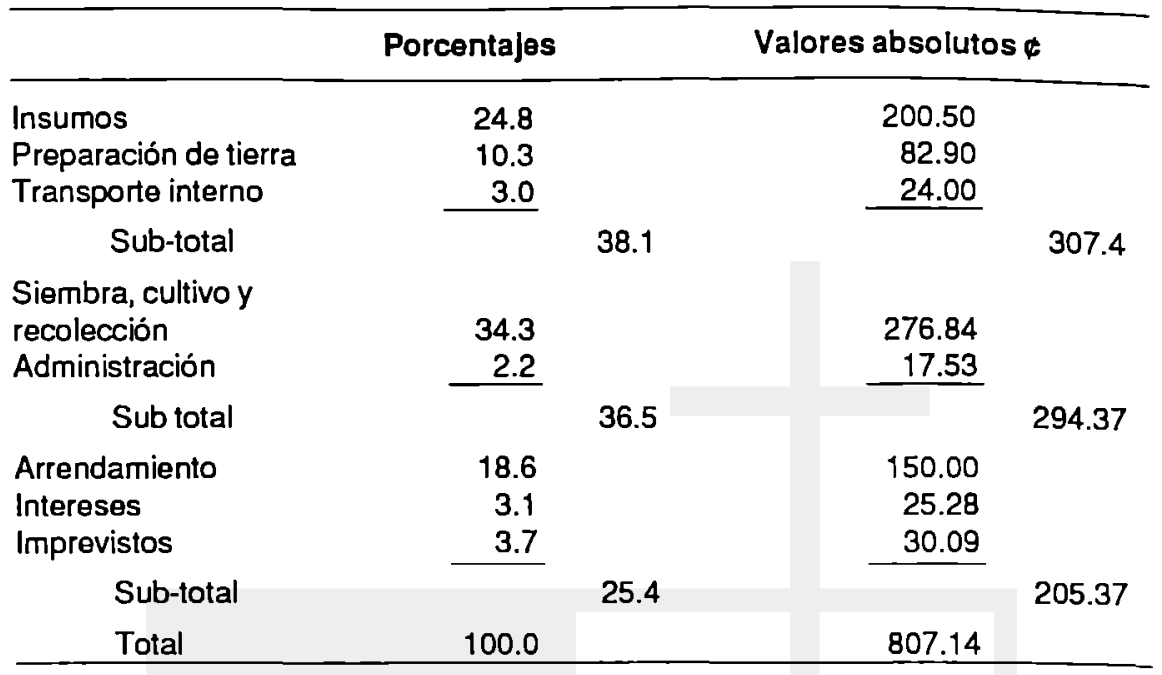

Fuente: Dirección General de Economia Agropecuaria. MAG. (ver Anexo No. 1)

ese año de 586.92 colones por manzana y aún sigue el PANC vendiendo sus productos por debajo de sus costos de producción, aunque a él no le parezca asi.

Una segunda alternativa sería que pague renta e intereses. Veamos entonces cuáles costos se le "esfuman" al PANC. Obviamente los gastos de administración y los imprevistos, no los considera, pero ellos apenas reducen los costos en 47.53 . Veamos, entonces, cuáles tienen que pagar efectivamente. Estos serian: intereses, renta e insumos, los cuales ascienden a: $\$ 375.78$. comparados con los ingresos promedio obtenidos de la venta que son de $\$ 586.92$, resulta un saldo positivo de $\$ 211.14$.

Al igual que en el caso anterior vende sus productos por debajo de sus costos de producción, pero en tanto que obtiene un diferencial positivo le parece que puede seguir produciendo. Al fin y al cabo, las labores de preparación de la tierra, así como la siembra, cultivo y recolección, las efectúa él, su mujer y sus hijos.

En tercer lugar, cómo se figure la realidad el PANC y cuál sea ésta en verdad son cosas diferentes. Tanto en la primera alternativa como en la segunda, en cuanto el PANC vende sus productos por debajo de sus costos está siendo expoliado. Sus procesos de trabajo se convierten indirectamente en instrumentos de valorización extraordinaria del capital 
como un todo o bien, bajo sus modalidades particulares. Revelando, por tanto, su carácter indirectamente subsumido en el capital.

Además, en la segunda alternativa presentada aparecen dos mecanismos adicionales de expoliación, cuales son el pago de intereses y la renta de la tierra, el PANC no obtiene ni siquiera un ingreso equivalente a los costos salariales. En otras palabras los pagos de intereses y de renta los efectúa a costa de sacrificar su ingreso personal.

En cuanto a las razones que mueven al PANC a continuar produciendo granos básicos, asi como a su lógica de "peor es nada", como estrategia de sobrevivencia, ciertamente no podemos cuestionarlas. Como tampoco podemos pretender que develando el fenómeno de la expoliación, propia del carácter indirectamente subsumido del trabajo en el capital, aquella - la expoliación-va a desaparecer.

Por otra parte, importa observar cuál es la situación que presenta el PANC para 1986. ¿Continúa siendo expoliado? ¿Podrá continuar sobreviviendo? Desafortunadamente no fue posible obtener datos para la productividad promedio durante ese año, sin embargo podemos suponer que se mantuvo la del año anterior, la cual es superior que la media para el periodo 1978-85. Lo mismo que suponemos para el maiz, lo hacemos con el maicillo. En el caso del frijol preferimos usar la media ya que la productividad para 1985 es inferior que la media para el periodo. Sefialamos lo anterior, aunque pensamos que basta con analizar el caso del maiz, no obstante en los cuadros y anexos aparecen los datos para los tres productos.

Para 1986 los ingresos percibidos por el PANC por manzana cultivada de maiz ascienden a $\$ 905.85$. Si efectuamos el análisis considerando la segunda alternativa, esto es, contabilizando sólo los pagos efectivos por insumos, intereses y renta, obtenemos la suma de: $₫ 909.27$. Lo cual nos está indicando que para el PANC que arrienda tierra y usa créditos su estrategia de sobreviviencia se ha agotado.

Veamos entonces la primera alternativa, la del PANC que no paga intereses, ni renta. Su gasto sólo en insumos es de $₫ 633.45$, contra un ingreso de $₫ 905.85$, resulta aún un saldo positivo de $\$ 272.4$ que parece ser superior al que obtenía en 1978, bajo la segunda alternativa. Sin embargo, a precios constantes de 1978, tan sólo está percibiendo 490.87. Lo cual, obviamente, evidencia el deterioro de los términos de intercambio de los PANC de granos básicos y a su vez la tendencia a una mayor expoliación por parte del capital.

Pero bien, sigamos operando a precios corrientes y veamos qué posibilidades de sobrevivencia se le presentan a un PANC de granos básicos que cultive 10 manzanas y que no usa crédito. Supongamos 
adicionalmente que cultiva $5 \mathrm{mz}$ de maiz asociado con trijol y 5 con maicillo. Reduzcamos los costos del cultivo del frijol y del maicillo a un $50 \%$ de los insumos.

Costos de producción según supuestos

\begin{tabular}{lrrrr}
\hline & $1 \mathrm{Mz}$ & $5 \mathrm{Mz}$ & $10 \mathrm{Mz}$ & \multicolumn{1}{l}{ Total } \\
\hline Insumos para máiz & 633.45 & - & 6.334 .5 & 6.334 .5 \\
Insumos para frijol & 252.9 & 1.264 .5 & - & 1.264 .5 \\
Insumos para maicillo & 241.5 & 1.207 .5 & - & 1.207 .5 \\
\hline \multicolumn{1}{c}{ Total } & 1.127 .85 & 2.472 .0 & 6.334 .5 & 8.806 .5 \\
\hline
\end{tabular}

Fuente: Dirección General de Economla Agropecuaria.

Veamos ahorá que ingresos obtendria suponiendo que la productividad permanece constante:

Ingresos de producción

\begin{tabular}{lrrrr}
\hline & $1 \mathrm{Mz}$ & $5 \mathrm{Mz}$ & $10 \mathrm{Mz}$ & \multicolumn{1}{l}{ Total } \\
\hline Máiz & 905.85 & - & 9.058 .5 & 9.058 .5 \\
Frijol & 1.101 .00 & 5.505 .0 & & 5.505 .0 \\
Maicillo & 506.88 & 2.534 .4 & & 2.534 .4 \\
\hline \multicolumn{1}{c}{ Total } & 2.513 .73 & 8.039 .4 & 9.058 .5 & 17.097 .9 \\
\hline
\end{tabular}

Al comparar los ingresos brutos por producción con los costos de los insumos obtenemos una diferencia de \$8.291.4.

Si levantamos el supuesto de que se mantiene la productividad ya que resulta irreal, tenemos que el maicillo y el frijol al ser cultivados en forma asociada ven reducida su productividad en un $20 \%$, aproximadamente ${ }^{63}$. En cuanto al maiz no encontramos datos que nos permitan efectuar una estimación similar, aunque como el asocio es con este grano, podriamos suponer que experimenta la misma reducción en su rendimiento. Ajustando los ingresos brutos tendriamos para el maiz: $\$ 7.246 .8$, para el trijol: $\$ 4.404 .00$ y para el maicillo: $\$ 2.027 .5$, lo que nos daría un total de $\$ 13.678$. del cual al restarle los costos de producción en insumos obtendriamos una diferencia de 44.871 .8 en concepto de ingresos personales durante el año agrícola de 1986. 
Ahora bien, tal cifra de por si no nos dice nada. Pero si tenemos en cuenta que el gasto promedio en consumo de las "explotaciones subfamiliares", esto es aquellas de 1 a 9.99 has., fue estimado para 1975 en $\$ 2.062 .00$ a precios corrientes ${ }^{64}$ tal cifra a precios constantes de 1978 seria igual a $2.062 .00+0.6919=2.980 .20$ y si a su vez traducimos los $4.871 .8+3.33 .6=1.462 .30$ a precios constantes de $1978^{65}$, tenemos que, ni aún los PANC que se encuentran en ol tramo superior de las explotaciones sub-familiares pueden lograr una satisfacción de sus necesidades equivalente a las de 1975.

Otra forma de evaluar tal ingreso bruto, sería contrastarlo con el costo de la Canasta Básica Familiar de Alimentos, tipo C. , la cual para una familia de 5.3 miembros tenía para 1986, un costo anual aproximado de $\$ 4.511 .00^{66}$.

Pero quizás se podría creer que tal canasta resulta demasiado "suntuaria" para el hombre del carnpo ya que incluye carne, leche y huevos a diferencia de la tipo $E$, que se reduce a maiz, frijol, arroz, azúcar, grasas y sal, y que sólo representaba para el mismo ano un costo de $\$ 2.737 .0067$. $Y$ asi obtendrian un remanente del $43.8 \%$ de sus ingresos para sus otras necesidades.

Dado que nuestro productor imaginario no es un PANC típico, quizás para darnos una mejor idea de las implicaciones de la expoliación debemos acudir nuevamente a los beneficiarios del decreto 207 y observar cuales son sus condiciones alimentarias.

\section{Allmentación per cáplta anual} (Llbras)

\begin{tabular}{lrcr}
\hline Alimentos & $\begin{array}{c}\text { Consumo } \\
\text { promedlo }\end{array}$ & $\begin{array}{c}\text { Requerlmientos } \\
\text { minimos }\end{array}$ & Dlferencla \\
\hline Maiz & 335.52 & 184 & +151.22 \\
Frijol & 48.72 & 60 & -11.28 \\
Arroz & 24.48 & 48 & -23.52 \\
Huevos & 14.40 & 39 & -24.60 \\
Leche & 22.32 & 201 & -178.68 \\
Azúcar & 38.64 & 40 & -1.36 \\
Carne & 18.72 & 73 & -54.28 \\
\hline
\end{tabular}

Fuente: Segundo Perfil de Beneficiarios del Decreto 207. p. 12 
El diferencial negativo evidencia claramente que los beneficiarios del 207 no logran satisfacer los requerimientos mínimos alimenticios, excepción hecha del maiz que consumen más del requerido. Por ello quizás se nos llama "hombres de maíz". Pero bien, si esa era la situación para 1984 y la tendencia ha sido al deterioro en los términos de intercambio, o si se prefiere, al incremento en la expoliación. Y si además tenemos en cuenta que estos PANC obtienen ingresos adicionales, entre otros, de la venta de su fuerza de trabajo. Es válido sostener que la estrategia de sobrevivencia fundamentada en la PANC de granos básicos, excluslvamente, no puede ser viable en tanto sus procesos de trabajo continúen subsumidos indirectamente en el capital y la expoliación de que son objeto continúe incrementandose.

Confiando haber presentado a lo largo de este trabajo suficientes indicadores de la subsunción indirecta de los procesos de trabajo de los productores no capitalista en el capital, al punto de que sea razonable aceptar la existencia de tal fenómeno, damos por concluida esta parte de la investigación.

\section{Consideraciones flnales}

En gran medida el tipo de indicadores utilizados a fin de evidenciar la subsunción indirecta del trabajo en el capital ha estado determinado por la disponibilidad de datos a los que hemos tenido acceso; sin embargo nos parece haber logrado mostrar suficientemente que la existencia de las formas de producción no capitalista se explica en tanto sus procesos de trabajo se encuentran subsumidos indirectamdnte en el capital, esto es, en tanto sus procesos de trabajo están incluidos en el capital, convirtiéndose asl en instrumentos mediatos de su valorización y a su vez, subordinados al mismo, en tanto su existencia, como la forma misma de su existencia, está determinada por las necesidades del capital. Ahora bien, lo anterior se explicíta a través de la relación de expoliación que media entre los productores no capitalistas y el capital, en tanto que es el carácter subordinado al capital lo que posibilita la expoliación y ésta, la valorización extraordinaria del mismo.

* En cuanto a los PANC observamos los siguientes hechos:

1. Que los PANC son responsables en un elevado porcentaje de la producción de alimentos (granos básicos), lo cual implica dentro de la división social del trabajo la asignación de una producción que es vital, pero que al capital no le interesa en tanto los PANC produzcan "alimentos baratos". Por consiguiente, su existencia misma está determinada por el capital, lo cual indica su carácter subordinado al mismo.

2. La producción de "alimentos baratos", esto es, por debajo de sus costos de producción reales, tiene muchísimas implicaciones: 
a) EI hecho de que sean alimentos posibilita la producción para el consumo, lo cual se traduce en una auto-reproducción parcial de la fuerza de trabajo y consiguientemente, posibilita al capital el adquirirla a precios no equivalentes a su valor, lo cual es un indicador de subsunción indirecta en tanto los procesos de trabajo de los PANC posibiliten una valorización extraordinaria del capital.

b) El hecho de que los PANC vendan sus mercancias por debajo de sus costos de producción, contribuye a mantener "barata" la fuerza de trabajo asalariada por el capital, lo cual hace que sus procesos de trabajo se conviertan en instrumentos mediatos de valorización extraordinaria del capital.

c) El hecho de vender sus mercancias a unos precios que no guardan relación con los precios de las mercancías que ellos adquieren, ya sean estos medios de vida ó de producción, revela el llamado intercambio desigual, lo cual se traduce en una transferencia de valor desde los PANC hacia los sectores capitalistas. Pero a su vez existe una subordinación al capital en tanto no se posee un control sobre los precios de sus mercancias y tienen que aceptar los precios establecidos por el mercado capitalista al efectuar sus compras, esto por una parte, por otra dependen de la producción capitalista para abastecerse, la cual va modificando no sólo sus prácticas de consumo, sino sus procesos mismos de trabajo.

Por tanto, es claro que sus procesos de trabajo están subsumidos indirectamente en el capital.

d) Adicionalmente se muestra la expoliación como un hecho cuantificado, aunque sea en forma aproximada, a través de comparar sus ingresos con los costos reales de producir maíz, maicillo y frijol, lo cual viene no sólo a evidenciar el fenómeno de la subsunción indirecta, sino a su vez el papel del Estado como posibilitante de la expoliación a través del control de precios.

3. Otro hecho que se observa claramente es el papel del Estado al promover la existencia de la PANC, vía asistencia técnica, créditos y la emisión de decretos como el 207, que ha tenido por resultado la proliferación del minifundio. Práctica que como sefialabamos no es nueva. Pero no se limita a promover la existencia del PANC, sino que contribuye a la subordinación de sus procesos de trabajo a través de la asistencia técnica y a posibilitar su expoliación mediante la fijación de precios de garantía al PANC, que se convierten en auténticos precios máximos. Los cuales no cubren los costos de producción, ni son los precios a que realiza mayoritariamente sus mercancias el PANC.

En lo que respecta al PANC nos parece que, sin excepción, hay 
suficientes indicadores que permiten sostener que las cinco hipótesis presentadas corresponden a la realidad empírica.

* Por tanto, si el conjunto de categorias articuladas en hipótesis, dan cuenta de la realidad de los productores no capitalistas, esto es, permiten su comprensión y explicación, podemos sostener que hemos presentado los fundamentos de una teoría que nos permita explicar una característica propia de los paises del sub-mundo capitalista, cual es la persistencia de formas de producción y circulación no capitalista, al menos para el caso de El Salvador, hacemos extensiva la explicación hasta las formas de circulación no capitalista, ya que si se explica la producción que es lo primario, con mayor razón puede ser explicada la circulación. Esta aseveración, de hecho se constituye en una hipótesis que será preciso investigar."

Importa también sefalar que el develar el fenómeno de la expoliación, no acabará con la misma; sin embargo, es necesario comprenderla primero a fin de sefialar los limites que presentan las pretendidas soluciones a los problemas de los productores no capitalistas, bajo cualquiera de sus formas particulares: Asi como para que el productor no capitalista tome conciencia de que sus intereses económicos están contrapuestos a los de la clase capitalista y pueda así, tomar una posición politica acorde cQn sus intereses reales, a diferencia de lo que sucede en la actualidad. Aseveración que también se constituye en una nueva hipótesis.

También nos parece que es preciso recalcar el papel del Estado, como instrumento de subsunción indirecta, en tanto que demasiado a menudo se espera de éste más de lo que pueda lograr, o bien, se observa en sus acciones meramente el aspecto político de las mismas, sin reparar en su trascendencia hasta el campo de lo económico; aunque las intenciones que motivaron una detemrinada medida, cual es el caso del decreto 207, hayan sido exclusivamente políticas, su impacto mayor ha sido en lo económico. Quizás este sea el sentido en que debemos entender aquel postulado marxista de que las leyes económicas se imponen independientemente de la voluntad de los hombres; la presencia de las formas de producción y circulación no capitalistas es una ley en los países del submundo capitalista, así como el carácter indirectamente subsumido de sus procesos de trabajo en el capital. Nueva aseveración con carácter hipotético.

- Deseamos también señalar que si alguna validez teórica presenta nuestro trabajo ello radicaría en el principio epistemológico del cual partimos y en el intento de aplicación del método de elevare de lo abstracto a lo concreto, asi como en los fundamentos teóricos de los cuales par-

\footnotetext{
- Vease Revista Realidad Económico-Social. Julio-Agosto 1988.
} 
timos, los cuales una y otra vez, evidencian su validez a fin de comprender y explicar la realidad del capitalismo. Más no exigiendo que la realidad se ajuste a la teoría, sino haciendo teoria adecuada a la realidad particular de la cual nos ocupamos. Tal ha sido el esfuerzo que hemos realizado a lo largo de estas páginas. Ciertamente no pretende ser algo acabado, pero si presenta los elementos básicos necesarios para continuar caminando en esta misma línea y lograr dar cuenta de la totalidad de las formas de producción y circulación no capitalistas, no sólo al nivel que hemos dejado planteado nuestro desarrollo en este trabajo, sino avanzando hasta concretos pensados que tengan un mayor grado de correspondencia con los concretos empiricos.

- Por otra parte, ha sido interesante constatar como las categorias económicas burguesas trascienden hasta el análisis de la producción no capitalista, dando lugar a nociones fetichizantes de la realidad de los productores no capitalistas. Tales son por ejemplo el uso de las categorias de "ganancias", "pérdidas", "ingreso neto". O bien, el ignorar ciertos costos se producción reales, cual es el caso de los costos derivados de los medios de vida los productores no capitalistas. En tanto que este productor no se paga asi mismo un salario, ni lo hace con los miembros de su familia, pareciera ser que ellos no incurren en ningún gasto, como si para iniciar un proceso de trabajo ó de producción no se requiere además de medios de producción, medios de vida.

En el análisis de los PANC nos interesó develar el fetichismo del ingreso neto, particularmente para los "beneficiarios del decreto 207", -aunque es válido para cualquier producción no capitalista - en tanto que el régimen busca justificar una de sus reformas a partir de cuantificaciones tales como la del ingreo neto, como un indicador de la mejoria de los PANC, beneficiados con tal decreto. Cuando la realidad es todo lo contrario, como lo evidenciamos en uno de los apartados.

- Para concluir consideramos necesario señalar que la expoliación de que son objeto los productores no capitalistas en tanto que es inherente a la relación de estos productores con el capital, no puede ser eliminada a menos que desapareciera cualquiera de los miembros de la relación, o bien ambos.

Sin embargo, cabe preguntarse: ¿No existirá la posibilidad de que a través de medidas de politica económica pueda atenuarse la magnitud de la expoliación? Teóricamente parece que una política de precios podría ser efectiva como atenuante, ya que la expoliación presupone un intercambio de no equivalentes.

Ahora bien, no se crea que por ser teóricamente sencillo sea fácil su implementación. Sobre todo si tenemos en cuenta que en el submundo capitalista, la valorización del capital se ha apoyado en la expoliación. De 
alli que lo más probable es que la efectividad de la política de precios, implique un trastocamiento de casi toda la estructura económica. Tómese tan sólo como un señalamiento para aquellos que esperan de la política económica más de lo que ella pueda dar de si. O dicho en otros términos, hay muchisimos problemas que exigen mucho más que medidas de política económica.

\section{Notas}

1. Lautier, Bruno. "La subsunción Formal del Trabajo al Capital". Revista Estudios Sociales Centroamericanos No. 13. Costa Rica, enero-abril de 1976. Pág. 162.

2. Esteva, Gustavo. "La Economía Campesina Actual como opción de Desarrollo". Investigación Económica. Vol. XXXVIII No. 147. México, eneromarzo de 1979. Pág. 237.

3. Op. Cit. Lautier p. 163.

4.. Ibid. Pág. 164.

5. Citado por Ann Lucas en "El Debate sobre los campesinos y el Capitalismo en México". Comercio Exterior Vol. 32, Núm. 4, México. Abril de 1982. Pág. 374.

6. Op. cit. Lautier, p. 136.

7. Ibid. Pág. 163.

8. Ibid. Pág. 164.

9. Ibld. Pág. 164.

10. Ibid. Pág. 165.

11. Ibid. Pág. 160.

12. Marx, Karl. Elementos Fundamentales para la crítica de la Economia Política (borrador) 1857-1858. Vol. 1, Edit. Siglo XXI, México 1971. Pág. 28.

13. Zamosc, León. "Producción Campesina y subsunción del trabajo en el Capital". Revista Desarrollo Indoamericano No. 50, Año XIV, Colombia, julio de 1979.

14. Ibid. Pág. 44.

15. Ibid. Pág. 45.

16. Ibid. Pág. 46.

17. Lucas, Ann, Op. Cit.

18. Ibid. Pág. 373.

19. Zamosc. Op. Cit. Pág. 45.

20. Lucas, Op. cit. Pág. 381.

21. Ibid. Pág. 382.

22. Ibid. ág. 382.

23. Beaud, Michel y otros. Para leer el Capitalismo. Edit. Nueva Imagen. México 1980, Págs. 86-87.

24. Ibid. Pág. 89.

25. Rubio, Roberto. Las formas generales de dominio del capital sobre el trabajo dentro de la agricultura salvadoreña. Tesis para optar al grado de Licenciado en Economía. Universidad Centroamericana "José Simeón Cañas". UCA, Marzo 1979. Pág. 22. 
26. Ibid. Pág. 26.

27. Ibid. Pág. 28.

28. Ibid. Pág. 31.

29. Ibid. Pág. 34.

30. Ibid. Págs 35-36.

31. Ibid. Págs. 37 y 38.

32. Ibid. Pág. 55

33. Ibid. Págs. 40-41.

34. Ibid. Págs. 41-42

35. Ministerio de Agricultura y Ganadería (MAG) VI Evaluación del Proceso de Reforma Agraria, OSPA-PERA. San Salvador, diciembre 1986. Págs. 4 y 30.

36. Ministerio de Agricultura y Ganaderla. Segundo Pertil de Beneficiarios del Decreto 207. OSPA-PERA. San Salvador, julio de 1985. Pág. 47.

37. Ibid. P. 43.

38. Ibid. P. 29.

39. Ibid. P. 29.

40. Ibid. P. 58.

41. Ibid. P. 65.

42. Ibid. P. 54.

43. Ibid. P. 25.

44. Ministerio de Economla. Dirección General de Estadísticas y Censos (DIGESTYC) Tercer Censo Nacional Agropecuario 1971. Volúmen I.

45. Op. cit. Segundo perfil. P. 82.

46. Ibid. P. 93.

47. Ibid. P. 72.

48. Fredéric Dévé. Apoyo a la Caracterización de los Productores de Granos Básicos del Istmo Centroamericano. Programa de Seguridad Alimentaria del istmo Centroamericano. CADESCA /CEE eje. II. Guatemala, octubre 1987. P. 89.

49. Op. cit. Segundo perfil P. 66.

50. Ministerio de Agricultura y Ganadería (MAG) OSPA. diagnóstico del Sistema Agropecuario 1960/75. Tomo I.P. 28.

51. Op. cit. Segundo perfil. P. 42.

52. Ministerio de Planificación. Política Nacional de Producción (Area Granos Básicos y Alimentos) San Salvador, mayo rde 1986. P. 61.

53. Op. cit. Segundo perfil . 49.

54. Op. cit. Tercer Censo Nacional Agropecuario.

55. Op. cit. Segundo perfil. P. 72.

56. Ibid. Págs. $64,77$.

57. Ibid. Pags. 49,40 y 39.

58. Ministerio de Agricultura y Ganadería. Dirección General de Economía Agropecuaria. Revista Economía Agropecuaria.

59. Op. cit. Segundo Pertil. P. 64.

60. Ministerio de Agricultura y Ganaderla (MAG) Oficina Sectorial de Planificación Agropecuaria (OSPA) "Diagnóstico General de la Producción de Alimentos Básicos: maiz, arroz, trijol y sorgo". San Salvador, febrero 1987. Págs. 39 y 47. 
61. Ibid. Págs. 19 y 20.

62. Ministerio de Agricultura y Ganaderla (MAG) Dirección General de Economla Agropecuaria. Vease anexos.

63. Estimación efectuada a partir de datos de la Dirección General de Economla Agropecuaria. MAG. Véase anexos.

64. Op. cit. Diagnóstico 1960/75. P. 282.

65. MIPLAN. Indicadores Económicos y Sociales. Enero-diciembre, 1985.

66. Estimación efectuada a partir de información de "Canasta Básica de Alimentos" MIPLAN-SECONAN. San Salvador, 1983.

67. Ibid.

\section{ANEXOS ESTADISTICOS}

Cuadro A

Indlce de preclos de granos béslcos a nlvel de productor

Base: $1978 / 1979=100$

\begin{tabular}{|c|c|c|r|}
\hline & Malz & Maicillo & Frljol \\
\hline 1978 & 100.0 & 100.0 & 100.0 \\
1979 & 74.6 & 100.0 & 78.4 \\
1980 & 85.0 & 114.0 & 150.3 \\
1981 & 95.9 & 128.7 & 145.7 \\
1982 & 94.0 & 125.6 & 120.8 \\
1983 & 105.0 & 134.4 & 97.4 \\
1984 & 109.0 & 128.6 & 88.7 \\
1985 & 103.5 & 133.0 & 111.1 \\
$1986^{*}$ & 151.5 & 223.5 & 167.4 \\
\hline
\end{tabular}

Fuenle: Estimados a partir de información de la Dirección General de Economla Agropecuaria. MAG.

- Indice promedio ponderado $=151.5 \times 0.73+223.5 \times 0.20+1657.4 \times 0.07=167.0$ 


\section{Cuadro B}

Indlce de productividad promedlo en la producclón

de granos béslcos

Base: $1978 / 1979=100$

\begin{tabular}{|c|c|c|c|}
\hline & Malz & Malclllo & Frljol \\
\hline $1978 / 79$ & 100.0 & 100.0 & 100.0 \\
$1979 / 80$ & 98.6 & 94.4 & 102.4 \\
$1980 / 81$ & 94.0 & 94.4 & 91.7 \\
$1981 / 82$ & 94.2 & 99.3 & 93.0 \\
$1982 / 83$ & 90.4 & 74.6 & 82.9 \\
$1983 / 84$ & 95.5 & 93.9 & 90.5 \\
$1984 / 85$ & 113.0 & 102.2 & 101.6 \\
$1985 / 86$ & 101.7 & 97.8 & 67.1 \\
$1986 / 87$ & 101.7 & 97.8 & 87.3 \\
\hline
\end{tabular}

Fuente: Calculados en base a rendimientos promedio de granos básicos 1970-84 (qq/mz). Dirección General de Economla Agropecuaria. MAG. (Ulimo año estimado)

\section{Cuadro C}

Indice de preclos de insumos utllizados en la producción de granos báslcos

Base: $1978 / 1979=100$

\begin{tabular}{|c|c|c|c|}
\hline & Malz & Malclllo & Frljol \\
\hline $1978 / 79$ & 100.0 & 100.0 & 100.0 \\
$1979 / 80$ & 122.8 & 152.2 & 148.3 \\
$1980 / 81$ & 175.8 & 185.3 & 246.3 \\
$1981 / 82$ & 208.7 & 315.8 & 296.5 \\
$1982 / 83$ & 202.7 & 307.0 & 296.5 \\
$1983 / 84$ & 164.4 & 306.0 & 290.0 \\
$1984 / 85$ & 208.8 & 270.7 & 178.6 \\
$1985 / 86$ & 185.3 & 308.4 & 193.1 \\
$1986 / 87$ & 315.9 & 525.0 & -301.1 \\
\hline
\end{tabular}

Fuente: Calculados a partir de los costos de producción estimados por la Dirección General de Economla Agropecuaria. MAG. 


\section{Cuadro D \\ Indice de costos de producclón por \\ manzana de granos básicos \\ Base: $1978 / 1979=100$}

\begin{tabular}{|c|c|c|c|}
\hline & Malz & Malclllo & Frijol \\
\hline $1978 / 79$ & 100.0 & 100.0 & 100.0 \\
$1979 / 80$ & 113.7 & 15.3 & 131.3 \\
$1980 / 81$ & 145.7 & 121.0 & 195.2 \\
$1981 / 82$ & 155.8 & 197.8 & 210.6 \\
$1982 / 83$ & 154.1 & 196.2 & 210.6 \\
$1983 / 84$ & 146.5 & 198.8 & 208.6 \\
$1984 / 85$ & 177.4 & 214.4 & 158.7 \\
$1985 / 86$ & 167.2 & 226.7 & 163.3 \\
$1986 / 87$ & 235.2 & 302.8 & 228.8 \\
\hline
\end{tabular}

Fuente: Calculados a partir de Costos de Producción estimados por la Dirección General de Economla Agropecuaria. MAG.

\section{Cuadro F \\ Preclos al productor \\ (\% porq q)}

\begin{tabular}{|c|c|c|c|}
\hline & Malz & Maiclllo & Frijol \\
\hline 1978 & 20.1 & 12.9 & 56.2 \\
1979 & 15.0 & 12.9 & 44.0 \\
1980 & 17.1 & 14.7 & 84.5 \\
1981 & 19.2 & 16.6 & 81.2 \\
1982 & 18.9 & 16.2 & 67.9 \\
1983 & 21.1 & 17.3 & 54.7 \\
1984 & 21.9 & 16.6 & 49.9 \\
1985 & 20.8 & 17.2 & 62.4 \\
1986 & 30.5 & 28.8 & 94.1 \\
$1978-1986$ & 20.5 & 17.0 & 66.6 \\
\hline
\end{tabular}

Fuento: Dirección General de Economia Agropecuaria. MAG (úttimos 3 años). Los 5 primeros años, la misma fuente pero estimados del precio del transportista menos el $17.0 \%$ para el maiz, el $21.0 \%$ para el maicillo y el $14.0 \%$ para el frijol que resulta ser el diferencial promedio para los años conocidos. 


\section{Cuadro G}

Ingresos brutos promedlos

(c por mz)

\begin{tabular}{|l|l|c|r|}
\hline & Malz & Malclllo & \multicolumn{1}{|c|}{ Frljol } \\
\hline 1978 & 586.92 & 232.20 & 753.08 \\
1979 & 432.00 & 219.30 & 563.20 \\
1980 & 470.25 & 261.60 & 980.20 \\
1981 & 528.00 & 297.14 & 958.23 \\
1982 & 498.96 & 257.58 & 712.95 \\
1983 & 578.14 & 292.37 & 623.58 \\
1984 & 722.70 & 305.44 & 638.72 \\
1985 & 617.76 & 302.72 & 561.60 \\
1986 & 905.85 & 506.88 & 1101.00 \\
$1978-1986$ & 593.40 & 297.25 & 765.84 \\
\hline
\end{tabular}

Fuento: Estimados a partir de cuadros A y B.

\section{Cuadro H \\ Costos de producclón de granos báslcos \\ (\$ por mz)}

\begin{tabular}{|l|c|c|c|}
\hline & Malz & Malclllo & \multicolumn{1}{|c|}{ Frljol } \\
\hline $1978 / 79$ & 807.14 & 575.33 & 631.83 \\
$1979 / 80$ & 917.75 & 663.52 & 829.30 \\
$1980 / 81$ & 1175.88 & 695.89 & 1233.58 \\
$1981 / 82$ & 1257.20 & 1138.11 & 1330.35 \\
$1982 / 83$ & 1243.50 & 1128.75 & 1330.35 \\
$1983 / 84$ & 1182.47 & 1143.69 & 1317.76 \\
$1984 / 85$ & 1492.21 & 1233.46 & 1002.62 \\
$1985 / 86$ & 1349.52 & 1304.37 & 1031.61 \\
$1986 / 87$ & 1898.47 & 1742.29 & 1445.46 \\
$1978 / 79-1986 / 87$ & 1251.57 & 1069.49 & 1128.10 \\
\hline
\end{tabular}

Fuenta: Dirección General de Economla Agropecuaria. MAG. 